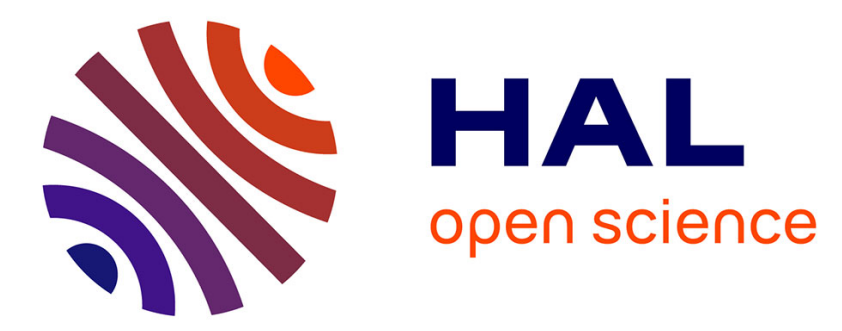

\title{
Lipopolythiourea Transfecting Agents: Lysine Thiourea Derivatives
}

\author{
Jeanne Leblond, Nathalie Mignet, Celine Largeau, Johanne Seguin, Daniel \\ Scherman, Jean Herscovici
}

\section{- To cite this version:}

Jeanne Leblond, Nathalie Mignet, Celine Largeau, Johanne Seguin, Daniel Scherman, et al.. Lipopolythiourea Transfecting Agents: Lysine Thiourea Derivatives. Bioconjugate Chemistry, 2007, 10.1021/bc7001924 . hal-02512550

\section{HAL Id: hal-02512550 \\ https://hal.science/hal-02512550}

Submitted on 23 Mar 2020

HAL is a multi-disciplinary open access archive for the deposit and dissemination of scientific research documents, whether they are published or not. The documents may come from teaching and research institutions in France or abroad, or from public or private research centers.
L'archive ouverte pluridisciplinaire $\mathbf{H A L}$, est destinée au dépôt et à la diffusion de documents scientifiques de niveau recherche, publiés ou non, émanant des établissements d'enseignement et de recherche français ou étrangers, des laboratoires publics ou privés. 


\title{
Lipopolythiourea transfecting agents: lysine thiourea
}

\section{derivatives.}

\author{
Jeanne Leblond, Nathalie Mignet*, Céline Largeau, Johanne Seguin, Daniel Scherman and Jean
} Herscovici*

Inserm, U640, Paris, F-75006 France; CNRS, UMR8151, Paris, F-75006 France; Ecole Nationale Supérieure de Chimie de Paris, Paris, F-75005; Unité de Pharmacologie Chimique et Génétique, France; Université Paris-Descartes, Faculté de Pharmacie, Paris, F-75270 France; Chimie Moléculaire de Paris Centre, CNRS, FR 2769, Paris, F-75005.

* Nathalie.Mignet@univ-paris5.fr; jean-herscovici@enscp.fr

TITLE RUNNING HEAD: Lipopolythioureas: new noncationic vector for gene transfer

ABSTRACT: Synthetic vectors represent an alternative to recombinant viruses for gene transfer. We have recently explored the transfection potential of a class of noncationic lipids bearing thiourea moieties as DNA associating headgroups. The encouraging results obtained with lipopolythioureas derived from serinol prompted us to investigate further this family of vectors. In the present study, we considered the transfection properties of a series of derivatives based on a different thiourea polar headgroup bearing a lysine scaffold. The synthesis of these compounds could be readily achieved in 3 steps with good yields. We found that these lipopolythioureas (LPT) might be considered as alternative systems for gene transfection, since their activity reached the same magnitude range as cationic vectors in the presence of serum. LPT with 14-carbon length chains appeared to be more efficient as transfecting agent than the ones with shorter chains. Toxicity studies proved that the hydration film 
method led to particles well tolerated both by the cells in vitro and by the mice in vivo. The ability to induce gene expression in vivo was demonstrated by intratumoral injection. Finally, biodistribution studies showed that the quantity recovered in the blood circulation, $2 \mathrm{~h}$ after systemic injection, was improved as compared to cationic lipids.

\section{INTRODUCTION}

Gene delivery requires, in most cases, a vector to protect DNA from enzymatic degradation and to allow DNA cellular uptake. Synthetic (1) and viral vectors (2) are currently being developed as gene delivery systems. Among artificial vectors, cationic lipids (3) and polymers (4) are particularly attractive as they can be easily prepared and have been extensively characterized (5). However, their cationic charges lead to nonspecific interaction with anionic serum components, strongly decreasing their transfection efficiency $(6,7)$ and inducing unspecific delivery in vivo $(8)$. Numerous studies have been undertaken to improve serum resistance by hiding the cationic charges $(9,10,11)$. Alternative delivery systems have been introduced, using nonelectrostatic interaction with DNA. For instance, Aoyama et al. succeeded to trap DNA in virus-like saccharidic clusters (12), and Barthelemy et al. developed nucleoside-based amphiphiles associating plasmids (13). However, with the exception of artificial glycovirus (14) these systems required a cationic charge to show some transfection activity in vitro (15). Strictly neutral systems, like liposomes (16) or spherulites (17), have been worked out for gene delivery, but, to the best of our knowledge, they have not shown any transfection properties.

Recent studies from our laboratory $(18,19)$ demonstrated the feasibility of using bis-thiourea as a noncationic lipid headgroup for gene transfer both in vitro and in vivo (20). Thiourea moieties are strong hydrogen bond donors and are able to interact with a wide range of derivatives including carbohydrates, carboxylates (21), nitrate (22) and phosphate groups (23). This last acid derivative is known to lead to the strongest interactions (24). These properties, together with their structural potential variety, make them good candidates to develop alternative vectors for gene transfer based on non-electrostatic interaction. In our growing interest in noncationic delivery systems based on thiourea interacting 
groups, we developed a new family of lipopolythioureas (LPT) lipids designed around a 2,6bis(thiocarbamoyl-amino)hexanoic acid scaffold. The new transfecting agents, described here, are readily available from lysine. In this paper, we describe the synthesis of these compounds, and present their transfection efficiency data, cytotoxicity studies and in vivo behavior.

\section{EXPERIMENTAL PROCEDURES}

\section{Materials and methods}

All solvents were purchased from Carlo Erba-SDS (Peypin France). Dichloromethane was distilled from $\mathrm{P}_{2} \mathrm{O}_{5}$. DMF was dried over $3 \AA$ molecular sieves and pyridine over $\mathrm{KOH}$. All chemicals were purchased from Sigma-Aldrich-Fluka or Lancaster. Tosyl chloride (petroleum ether) and cholesteryl chloroformate (acetone) were recrystallized, diglycolic anhydride was dehydrated $\left(\mathrm{P}_{2} \mathrm{O}_{5}\right)$ prior to use. Other solvents and products were used without further purification. Reactions were monitored by thinlayer chromatography using Merck precoated 60 F254 silica gel plates. Column chromatography was performed over SDS (Peypin France) 35-70 m silicagel according to the method of Still, Khan, and Mitra (25) or using small column flash chromatography (SFC) according to the following procedure: a plastic syringe was filled with silicagel (product/silicagel 1/5) and connected to a vacuum pump. The column was equilibrated with heptane then the sample, dissolved in a minimum of dichloromethane, was added to the top. The column was eluted by ten fractions (volume equal to the silicagel volume) of a heptane/ethyl acetate mixture. For each fraction the amount of ethyl acetate was increased $(10 \%$ to $100 \%(\mathrm{v} / \mathrm{v})$ heptane in ethyl acetate). Inverse phase SPE was performed on Supelco Superclean C8 cartridge using $\mathrm{H}_{2} \mathrm{O} / \mathrm{CH}_{3} \mathrm{CN} / \mathrm{CH}_{3} \mathrm{OH}$ mixture. ${ }^{1} \mathrm{H}$ and ${ }^{13} \mathrm{C}$ NMR spectra were recorded on a BRUKER Avance DRX-300 spectrometer at $300.13 \mathrm{MHz}$ for the proton and $75.47 \mathrm{MHz}$ for the carbon. NMR spectra were processed using Xwinnmr (Bruker) or SwaN-MR (26). MS were carried out on a Shimazu 2010A LC-MS on ESI mode. High resolution MS and elemental analysis were carried out by the "Service Central de Micro-analyse du CNRS", Vernaison France. Dipalmytoylphosphatidylcholine (DPPC), Dioleylphosphatidylethanolamine (DOPE) and phosphatidylethanolamine-lissamine rhodamine 
were purchased from Aventi Polar Lipids (Alabaster Alabama). Polyethyleneimine (PEI) was purchased from Sigma-aldrich-Fluka. The lipopolyamine 2-\{3-[Bis-(3-amino-propyl)-amino]-propylamino\}-Nditetradecylcarbamoyl methyl-acetamide (RPR209120) was previously prepared in our laboratory, the synthesis is described in the supplementary information of reference (9) Plasmid pVax1 was provided by Invitrogen.

\section{Synthesis of lipolythioureas.}

\section{(S)-tert-butyl [1-(didecylcarbamoyl)-6-tert-butoxycarbonylamino-hexyl]aminoformate (3a)}

N-hydroxysuccinimide $(0.093 \mathrm{~g}, 0.81 \mathrm{mmol})$ and $N, N^{\prime}$-dicyclohexylcarbodiimide (DCC) (0.42 g, 2.03 mmol) were added to a solution of acid $2(0.28 \mathrm{~g}, 0.81 \mathrm{mmol})$ in dry THF $(30 \mathrm{~mL})$. The solution was stirred for one hour before the addition of didecylamine 1a $(0.20 \mathrm{~g}, 0.68 \mathrm{mmol})$. The stirring was followed during $17 \mathrm{~h}$ then the reaction mixture was diluted with dichloromethane and washed twice with water. The organic layer was dried $\left(\mathrm{MgSO}_{4}\right)$ and evaporated under reduced pressure. The resulting oil was purified first by SFC then by flash chromatography (heptane/ethyl acetate 9/1) to yield 3a as an oil $(0.32 \mathrm{~g}, 63 \%) .{ }^{1} \mathrm{H}$ NMR $\left(\mathrm{CDCl}_{3}\right) \delta(\mathrm{ppm}) 0.88\left(\mathrm{t}, 6 \mathrm{H}, J=6.0 \mathrm{~Hz}, \mathrm{CH}_{3}\right), 1.26\left(\mathrm{~m}, 30 \mathrm{H},-\mathrm{CH}_{2}-\right), 1.43$ $\left(\mathrm{s}, 9 \mathrm{H},\left(\mathrm{CH}_{3}\right)_{3}\right), 1.45\left(\mathrm{~m}, 2 \mathrm{H},-\mathrm{CH}_{2}-\right), 1.55\left(\mathrm{~m}, 4 \mathrm{H},-\mathrm{CH}_{2}-\right), 1.80\left(\mathrm{~m}, 2 \mathrm{H}, \mathrm{CH}_{2}\right), 3.11\left(\mathrm{~m}, 2 \mathrm{H},-\mathrm{CH}_{2} \mathrm{~N}\right)$, $3.25\left(\mathrm{~m}, 2 \mathrm{H},-\mathrm{CH}_{2} \mathrm{~N}\right), 3.47\left(\mathrm{~m}, 2 \mathrm{H},-\mathrm{CH}_{2} \mathrm{~N}\right), 4.52(\mathrm{~m}, 1 \mathrm{H}, \mathrm{CH}), 4.54(\mathrm{~m}, 1 \mathrm{H}, \mathrm{NH}), 5.35(\mathrm{~d}, 1 \mathrm{H}, J=7.5$ $\mathrm{Hz}, \mathrm{NH}) .{ }^{13} \mathrm{C} \mathrm{NMR}\left(\mathrm{CDCl}_{3}\right) \delta(\mathrm{ppm}) 14.11\left(\mathrm{~s}, \mathrm{CH}_{3}\right), 22.73\left(\mathrm{~m},-\mathrm{CH}_{2}-\right), 27.05\left(\mathrm{~s},-\mathrm{CH}_{2}-\right), 27.67(\mathrm{~s},-$ $\left.\mathrm{CH}_{2}-\right), 28.45\left(\mathrm{~s},\left(\mathrm{CH}_{3}\right)_{3}\right), 29.62\left(\mathrm{~m},-\mathrm{CH}_{2}-\right), 31.95\left(\mathrm{~s},-\mathrm{CH}_{2}-\right), 33.09\left(\mathrm{~s}, \mathrm{CH}_{2}\right), 40.51\left(\mathrm{~s}, \mathrm{CH}_{2} \mathrm{~N}\right), 46.10(\mathrm{~s}$, $\left.\mathrm{CH}_{2} \mathrm{~N}\right), 47.86\left(\mathrm{~s}, \mathrm{CH}_{2} \mathrm{~N}\right), 49.92(\mathrm{~s}, \mathrm{CH}), 79.18\left(\mathrm{~s}, \mathrm{C}\left(\mathrm{CH}_{3}\right)_{3}\right), 79.80\left(\mathrm{~s}, \mathrm{C}_{\left.\left(\mathrm{CH}_{3}\right)_{3}\right),} 155.94(\mathrm{~s}, \mathrm{OC}=\mathrm{O})\right.$, $156.31(\mathrm{~s}, \mathrm{OC}=\mathrm{O}), 171.52(\mathrm{~s}, \mathrm{NC}=\mathrm{O})$.

\section{(S)-tert-butyl [1-(didodecylcarbamoyl)-6-tert-butoxycarbonylamino-hexyl]aminoformate (3b)}

N-hydroxysuccinimide $(0.24 \mathrm{~g}, 2.05 \mathrm{mmol})$ and DCC $(1.06 \mathrm{~g}, 5.1 \mathrm{mmol})$ were added to a solution of acid $2(0.71 \mathrm{~g}, 2.05 \mathrm{mmol})$ in dry THF $(60 \mathrm{~mL})$. The solution was stirred for two hours before addition of didodecylamine $\mathbf{1 b}(0.61 \mathrm{~g}, 1.72 \mathrm{mmol})$. The stirring was followed during $20 \mathrm{~h}$ then the reaction mixture was diluted with dichloromethane and washed twice with water. The organic layer was dried $\left(\mathrm{MgSO}_{4}\right)$ and evaporated under reduced pressure. The resulting oil was purified by flash 
chromatography (heptane/ethyl acetate $95 / 5)$ to yield $\mathbf{3 b}$ as an oil $(0.65 \mathrm{~g}, 46 \%) .{ }^{1} \mathrm{H}$ NMR $\left(\mathrm{CDCl}_{3}\right) \delta$ (ppm) $0.84\left(\mathrm{t}, 6 \mathrm{H}, J=6.0 \mathrm{~Hz}, \mathrm{CH}_{3}\right), 1.22\left(\mathrm{~m}, 38 \mathrm{H},-\mathrm{CH}_{2}-\right), 1.39\left(\mathrm{~s}, 9 \mathrm{H},\left(\mathrm{CH}_{3}\right)_{3}\right), 1.49\left(\mathrm{~m}, 2 \mathrm{H}, \mathrm{CH}_{2}\right)$, $1.54\left(\mathrm{~m}, 6 \mathrm{H},-\mathrm{CH}_{2}-\right), 3.06\left(\mathrm{~m}, 2 \mathrm{H},-\mathrm{CH}_{2} \mathrm{~N}\right), 3.22\left(\mathrm{~m}, 2 \mathrm{H},-\mathrm{CH}_{2} \mathrm{~N}\right), 3.45\left(\mathrm{~m}, 2 \mathrm{H},-\mathrm{CH}_{2} \mathrm{~N}\right), 4.49(\mathrm{~m}, 1 \mathrm{H}$, $\mathrm{CH}), 4.68(\mathrm{~m}, 1 \mathrm{H}, \mathrm{NH}), 5.36(\mathrm{~d}, 1 \mathrm{H}, J=8.7 \mathrm{~Hz}, \mathrm{NH}) .{ }^{13} \mathrm{C} \mathrm{NMR}\left(\mathrm{CDCl}_{3}\right) \delta(\mathrm{ppm}) 14.09\left(\mathrm{~s}, \mathrm{CH}_{3}\right), 22.65$ (m, - $\left.\mathrm{CH}_{2}-\right), 26.99\left(\mathrm{~s},-\mathrm{CH}_{2}-\right), 27.63\left(\mathrm{~s},-\mathrm{CH}_{2}-\right), 28.42\left(\mathrm{~s},\left(\mathrm{CH}_{3}\right)_{3}\right), 29.38\left(\mathrm{~s},-\mathrm{CH}_{2}-\right), 29.62\left(\mathrm{~m},-\mathrm{CH}_{2}^{-}\right)$, $31.93\left(\mathrm{~s},-\mathrm{CH}_{2}-\right), 33.81\left(\mathrm{~s}, \mathrm{CH}_{2}\right), 40.43\left(\mathrm{~s},-\mathrm{CH}_{2} \mathrm{~N}\right), 46.07\left(\mathrm{~s},-\mathrm{CH}_{2} \mathrm{~N}\right), 47.83\left(\mathrm{~s},-\mathrm{CH}_{2} \mathrm{~N}\right), 49.89(\mathrm{~s}, \mathrm{CH})$, $78.95\left(\mathrm{~s}, \mathrm{C}\left(\mathrm{CH}_{3}\right)_{3}\right), 79.39\left(\mathrm{~s}, \mathrm{C}\left(\mathrm{CH}_{3}\right)_{3}\right), 155.56(\mathrm{~s}, \mathrm{OC}=\mathrm{O}), 156.03(\mathrm{~s}, \mathrm{OC}=\mathrm{O}), 171.92(\mathrm{~s}, \mathrm{C}=\mathrm{O}) . \mathrm{MS}$ $(\mathrm{ESI}, m / z) 682(\mathrm{M}+\mathrm{H})^{+}, 704(\mathrm{M}+\mathrm{Na})^{+}$.

\section{(S)-tert-butyl [1-(ditetradecylcarbamoyl)-6-tert-butoxycarbonylamino-hexyl]aminoformate (3c)}

N-hydroxysuccinimide $(0.17 \mathrm{~g}, 1.44 \mathrm{mmol})$ and DCC $(0.74 \mathrm{~g}, 3.60 \mathrm{mmol})$ were added to a solution of acid 2 in dry THF $(50 \mathrm{~mL})$. The solution was stirred for one hour before the addition of ditetradecylamine 1c $(0.50 \mathrm{~g}, 1.21 \mathrm{mmol})$. The stirring was continued for $20 \mathrm{~h}$ then the reaction mixture was diluted with dichloromethane and washed twice with water. The organic layer was dried $\left(\mathrm{MgSO}_{4}\right)$ and evaporated under reduced pressure. The resulting oil was purified by flash chromatography (heptane/ethyl acetate $95 / 5)$ to yield $3 \mathrm{c}$ as an oil $(0.73 \mathrm{~g}, 67 \%) .{ }^{1} \mathrm{H} \mathrm{NMR}\left(\mathrm{CDCl}_{3}\right) \delta(\mathrm{ppm}) 0.88(\mathrm{t}, 6 \mathrm{H}, J$ $\left.=6.0 \mathrm{~Hz}, \mathrm{CH}_{3}\right), 1.26\left(\mathrm{~m}, 30 \mathrm{H},-\mathrm{CH}_{2}-\right), 1.44\left(\mathrm{~s}, 9 \mathrm{H},\left(\mathrm{CH}_{3}\right)_{3}\right), 1.45\left(\mathrm{~m}, 2 \mathrm{H}, \mathrm{CH}_{2}\right), 1.58\left(\mathrm{~m}, 6 \mathrm{H},-\mathrm{CH}_{2}-\right)$, $3.11\left(\mathrm{~m}, 2 \mathrm{H},-\mathrm{CH}_{2} \mathrm{~N}\right), 3.25\left(\mathrm{~m}, 2 \mathrm{H}, \mathrm{CH}_{2} \mathrm{~N}\right), 3.49\left(\mathrm{~m}, 2 \mathrm{H},-\mathrm{CH}_{2} \mathrm{~N}\right), 4.52(\mathrm{~m}, 1 \mathrm{H}, \mathrm{CH}), 4.54(\mathrm{~m}, 1 \mathrm{H}, \mathrm{NH})$, $5.39(\mathrm{~d}, 1 \mathrm{H}, J=7.5 \mathrm{~Hz}, \mathrm{NH}) .{ }^{13} \mathrm{C} \mathrm{NMR}\left(\mathrm{CDCl}_{3}\right) \delta(\mathrm{ppm}) 14.17\left(\mathrm{~s}, \mathrm{CH}_{3}\right), 22.76\left(\mathrm{~m},-\mathrm{CH}_{2}-\right), 27.05(\mathrm{~s},-$ $\left.\mathrm{CH}_{2}-\right), 27.67\left(\mathrm{~s},-\mathrm{CH}_{2}-\right), 28.45\left(\mathrm{~s},\left(\mathrm{CH}_{3}\right)_{3}\right), 29.62\left(\mathrm{~m},-\mathrm{CH}_{2}-\right), 31.94\left(\mathrm{~s},-\mathrm{CH}_{2}-\right), 33.74\left(\mathrm{~s}, \mathrm{CH}_{2}\right), 40.40(\mathrm{~s}$, $\left.\mathrm{CH}_{2} \mathrm{~N}\right), 46.10\left(\mathrm{~s}, \mathrm{CH}_{2} \mathrm{~N}\right), 47.85\left(\mathrm{~s}, \mathrm{CH}_{2} \mathrm{~N}\right), 49.90(\mathrm{~s}, \mathrm{CH}), 79.38\left(\mathrm{~s}, \mathrm{C}\left(\mathrm{CH}_{3}\right)_{3}\right), 155.94(\mathrm{~m}, \mathrm{OC}=\mathrm{O})$, $171.85(\mathrm{~s}, \mathrm{C}=\mathrm{O})$. MS (ESI, $m / z) 760(\mathrm{M}+\mathrm{Na})^{+}$.

\section{(S)- 2,7-diamino-N,N-didecyl-heptanamide (4a)}

A solution of amide $3 \mathbf{a}(1.31 \mathrm{~g}, 2.1 \mathrm{mmol})$ in dichloromethane $(2 \mathrm{~mL})$ was treated with a TFA/ $\mathrm{CH}_{2} \mathrm{Cl}_{2}$ mixture $(3: 1,8 \mathrm{~mL})$. The reaction mixture was stirred for $24 \mathrm{~h}$ then was treated with solid $\mathrm{NaHCO}_{3}$, filtered and washed with water then $2 \mathrm{~N} \mathrm{NaOH}$ was added to the aqueous phase until $\mathrm{pH}$ 9. The water layer was extracted three times with dichloromethane. The organic layers were dried $\left(\mathrm{MgSO}_{4}\right)$ and 
evaporated under reduced pressure to yield $4 \mathbf{a}(0.9 \mathrm{~g}, 100 \%)$ as a yellow oil, which was used without further purification. ${ }^{1} \mathrm{H} \mathrm{NMR}\left(\mathrm{CDCl}_{3}\right) \delta(\mathrm{ppm}) 0.87\left(\mathrm{t}, 6 \mathrm{H}, J=6.0 \mathrm{~Hz}, \mathrm{CH}_{3}\right), 1.26\left(\mathrm{~m}, 30 \mathrm{H},-\mathrm{CH}_{2}-\right), 1.55$ (m, 6H, - $\left.\mathrm{CH}_{2-}\right), 1.65\left(\mathrm{~m}, 2 \mathrm{H}, \mathrm{CH}_{2}\right), 2.03(\mathrm{~m}, 4 \mathrm{H}, \mathrm{NH}), 2.72\left(\mathrm{~m}, 2 \mathrm{H}, \mathrm{CH}_{2} \mathrm{NH}_{2}\right), 3.11\left(\mathrm{~m}, 2 \mathrm{H},-\mathrm{CH}_{2} \mathrm{~N}\right)$, $3.24\left(\mathrm{~m}, 2 \mathrm{H}, \mathrm{CH}_{2} \mathrm{~N}\right), 3.52(\mathrm{~m}, 2 \mathrm{H}, \mathrm{CH}), 5.40(\mathrm{~m}, 1 \mathrm{H}, \mathrm{NH}) . \delta(\mathrm{ppm}) 14.13\left(\mathrm{~s}, \mathrm{CH}_{3}\right), 22.74\left(\mathrm{~s},-\mathrm{CH}_{2}-\right)$, $23.22\left(\mathrm{~s},-\mathrm{CH}_{2}-\right), 27.08\left(\mathrm{~s},-\mathrm{CH}_{2}-\right), 27.78\left(\mathrm{~s},-\mathrm{CH}_{2}-\right), 29.62(\mathrm{~m},-\mathrm{CH} 2-), 31.94\left(\mathrm{~s},-\mathrm{CH}_{2}-\right), 33.06\left(\mathrm{~s}, \mathrm{CH}_{2}\right)$, $41.74\left(\mathrm{~s}, \mathrm{CH}_{2} \mathrm{NH}_{2}\right), 46.28\left(\mathrm{~s}, \mathrm{CH}_{2} \mathrm{~N}\right), 47.55\left(\mathrm{~s}, \mathrm{CH}_{2} \mathrm{~N}\right), 51.17(\mathrm{~s}, \mathrm{CH}), 173.05(\mathrm{~s}, \mathrm{C}=\mathrm{O})$.

\section{(S)- 2,7-diamino-N,N-didodecyl-heptanamide (4b)}

A solution of amide $3 \mathbf{b}(0.65 \mathrm{~g}, 0.95 \mathrm{mmol})$ in dichloromethane $(2 \mathrm{~mL})$ was treated with a TFA/ $\mathrm{CH}_{2} \mathrm{Cl}_{2}$ mixture $(3: 1,5 \mathrm{ml})$. The reaction mixture was stirred for $3 \mathrm{~h}$ then it was treated with solid $\mathrm{NaHCO}_{3}$, filtered and washed with water. $\mathrm{NaOH} 2 \mathrm{~N}$ was added to the aqueous phase until $\mathrm{pH}$ 9. The water layer was extracted three times with dichloromethane. The organic layers were dried $\left(\mathrm{MgSO}_{4}\right)$ and evaporated under reduced pressure to yield $\mathbf{4 b}(0.5 \mathrm{~g}, 100 \%)$ as a yellow oil, which was used without further purification. ${ }^{1} \mathrm{H}$ NMR $\left(\mathrm{CDCl}_{3}\right) \delta(\mathrm{ppm}) 0.86\left(\mathrm{t}, 6 \mathrm{H}, J=6.0 \mathrm{~Hz}, \mathrm{CH}_{3}\right), 1.23(\mathrm{~m}, 38 \mathrm{H}$, $\left.\mathrm{CH}_{2-}\right), 1.49\left(\mathrm{~m}, 6 \mathrm{H},-\mathrm{CH}_{2}-\right), 2.94\left(\mathrm{~m}, 2 \mathrm{H}, \mathrm{CH}_{2} \mathrm{NH}_{2}\right), 3.11\left(\mathrm{~m}, 4 \mathrm{H}, \mathrm{CH}_{2} \mathrm{~N}\right), 3.80(\mathrm{~m}, 2 \mathrm{H}, \mathrm{CH}), 6.24(\mathrm{~m}$, 4H, NH). ${ }^{13} \mathrm{C} \mathrm{NMR}\left(\mathrm{CDCl}_{3}\right) \delta(\mathrm{ppm}) 14.09\left(\mathrm{~s}, \mathrm{CH}_{3}\right), 21.89\left(\mathrm{~s},-\mathrm{CH}_{2}-\right), 22.71\left(\mathrm{~s},-\mathrm{CH}_{2}-\right), 27.12\left(\mathrm{~s},-\mathrm{CH}_{2}-\right.$ ), $27.51\left(\mathrm{~s},-\mathrm{CH}_{2}-\right), 29.70(\mathrm{~m},-\mathrm{CH} 2-), 31.96\left(\mathrm{~s},-\mathrm{CH}_{2}-\right), 33.94\left(\mathrm{~s}, \mathrm{CH}_{2}\right), 39.16\left(\mathrm{~s}, \mathrm{CH}_{2} \mathrm{NH}_{2}\right), 46.50(\mathrm{~s}$, $\left.\mathrm{CH}_{2} \mathrm{~N}\right), 47.72\left(\mathrm{~s}, \mathrm{CH}_{2} \mathrm{~N}\right), 50.73(\mathrm{~s}, \mathrm{CH}), 173.10(\mathrm{~s}, \mathrm{C}=\mathrm{O}) . \mathrm{MS}(\mathrm{ESI}, \mathrm{m} / z) 483(\mathrm{M}+\mathrm{H})^{+}, 262$ $((\mathrm{M}+2 \mathrm{H}+2 \mathrm{Na}) / 2)^{+}$

\section{(S)-2,7-diamino-N,N-ditetradecyl-heptanamide (4c)}

A solution of amide $3 \mathrm{c}(0.73 \mathrm{~g}, 1 \mathrm{mmol})$ in a TFA $/ \mathrm{CH}_{2} \mathrm{Cl}_{2}$ mixture $(4: 1,5 \mathrm{ml})$ was stirred for $3 \mathrm{~h}$. Then the reaction mixture was treated with solid $\mathrm{NaHCO}_{3}$, filtered, and washed with water. $2 \mathrm{~N} \mathrm{NaOH}$ was added to the aqueous phase until $\mathrm{pH}$ 9. The water layer was extracted three times with dichloromethane. The organic layers were dried $\left(\mathrm{MgSO}_{4}\right)$ and evaporated under reduced pressure to yield $4 \mathrm{c}(0.36 \mathrm{~g}, 68 \%)$ as a yellow oil, which was used without further purification. ${ }^{1} \mathrm{H} \mathrm{NMR}\left(\mathrm{CDCl}_{3}\right) \delta$ (ppm) $0.86\left(\mathrm{t}, 6 \mathrm{H}, J=6.0 \mathrm{~Hz}, \mathrm{CH}_{3}\right), 1.23\left(\mathrm{~m}, 30 \mathrm{H},-\mathrm{CH}_{2}-\right), 1.47\left(\mathrm{~m}, 6 \mathrm{H},-\mathrm{CH}_{2}-\right), 1.88\left(\mathrm{~m}, 2 \mathrm{H}, \mathrm{CH}_{2}\right)$, $2.81\left(\mathrm{~m}, 2 \mathrm{H}, \mathrm{CH}_{2} \mathrm{NH}_{2}\right), 3.10\left(\mathrm{~m}, 2 \mathrm{H}, \mathrm{CH}_{2} \mathrm{~N}\right), 3.24\left(\mathrm{~m}, 2 \mathrm{H}, \mathrm{CH}_{2} \mathrm{~N}\right), 3.47(\mathrm{~m}, 2 \mathrm{H}, \mathrm{CH}), 5.40(\mathrm{~m}, 1 \mathrm{H}, \mathrm{NH})$. 
${ }^{13} \mathrm{C} \mathrm{NMR}\left(\mathrm{CDCl}_{3}\right) \delta(\mathrm{ppm}) 14.12\left(\mathrm{~s}, \mathrm{CH}_{3}\right), 22.72\left(\mathrm{~m},-\mathrm{CH}_{2}-\right), 27.10\left(\mathrm{~s},-\mathrm{CH}_{2}-\right), 27.70\left(\mathrm{~s},-\mathrm{CH}_{2}-\right), 29.70$

(m, - $\mathrm{CH}_{2-}$ ), $31.97\left(\mathrm{~s},-\mathrm{CH}_{2}-\right), 34.00\left(\mathrm{~s},-\mathrm{CH}_{2}-\right), 40.91\left(\mathrm{~s}, \mathrm{CH}_{2} \mathrm{NH}_{2}\right), 46.33\left(\mathrm{~s}, \mathrm{CH}_{2} \mathrm{~N}\right), 47.58\left(\mathrm{~s}, \mathrm{CH}_{2} \mathrm{~N}\right)$, $51.48(\mathrm{~s}, \mathrm{CH}), 171.85(\mathrm{~s}, \mathrm{C}=\mathrm{O}) . \mathrm{MS}(\mathrm{ESI}, \mathrm{m} / \mathrm{z}) 539(\mathrm{M}+\mathrm{H})^{+}$.

(S)-2,7-bis[(2,2-dimethyl-1,3-dioxolan-4-yl)methylthiocarbamoylamino]-N,N-didecyl-heptanamide

$(6 a)$

A solution of amine $4 \mathbf{a}(0.21 \mathrm{~g}, 0.5 \mathrm{mmol})$, and $N, N$-diisopropylethylamine $(0.87 \mathrm{~mL}, 5 \mathrm{mmol})$ in dichloromethane $(5 \mathrm{~mL})$ was stirred for $10 \mathrm{mn}$ before addition of isothiocyanate $5(0.22 \mathrm{~g}, 1.3 \mathrm{mmol})$. The reaction mixture was stirred overnight and evaporated under reduced pressure. Purification of the crude by SFC afforded 5a $(0.32 \mathrm{mg}, 83 \%)$ as a colorless oil. ${ }^{1} \mathrm{H}$ NMR $\left(\mathrm{CDCl}_{3}\right) \delta(\mathrm{ppm}) 0.86(\mathrm{t}, 6 \mathrm{H}, J=$ $\left.6.0 \mathrm{~Hz}, \mathrm{CH}_{3}\right), 1.24\left(\mathrm{~m}, 32 \mathrm{H},-\mathrm{CH}_{2}-\right), 1.31\left(\mathrm{~s}, 6 \mathrm{H},\left(\mathrm{CH}_{3}\right)_{2}\right), 1.33\left(\mathrm{~s}, 6 \mathrm{H},\left(\mathrm{CH}_{3}\right)_{2}\right), 1.43\left(\mathrm{~m}, 4 \mathrm{H}_{,}-\mathrm{CH}_{2}-\right)$, $1.66\left(\mathrm{~m}, 2 \mathrm{H},-\mathrm{CH}_{2}-\right), 3.20\left(\mathrm{~m}, 4 \mathrm{H}, \mathrm{CH}_{2} \mathrm{NCO}\right), 3.45\left(\mathrm{~m}, 2 \mathrm{H}, \mathrm{CH}_{2} \mathrm{NCS}\right) 3.68\left(\mathrm{~m}, 4 \mathrm{H}, \mathrm{CH}_{2} \mathrm{NCS}\right), 4.01(\mathrm{~m}$, $\left.4 \mathrm{H}, \mathrm{CH}_{2} \mathrm{O}\right), 4.27(\mathrm{~m}, 4 \mathrm{H}, \mathrm{CHO}), 5.55(\mathrm{~m}, 1 \mathrm{H}, \mathrm{CH}), 6.85(\mathrm{~m}, 2 \mathrm{H}, \mathrm{NH}), 7.85$ (m, 2H, NH). ${ }^{13} \mathrm{C} \mathrm{NMR}$ $(\mathrm{CDCl} 3) \delta(\mathrm{ppm}) 13.98\left(\mathrm{~s}, \mathrm{CH}_{3}\right), 22.72\left(\mathrm{~s},-\mathrm{CH}_{2}-\right), 23.40\left(\mathrm{~s},-\mathrm{CH}_{2}-\right), 25.30\left(\mathrm{~s},\left(\mathrm{CH}_{3}\right)_{2}\right), 27.05\left(\mathrm{~s},\left(\mathrm{CH}_{3}\right)_{2}\right)$, $27.71\left(\mathrm{~s},-\mathrm{CH}_{2}-\right), 28.76\left(\mathrm{~s},-\mathrm{CH}_{2}-\right), 29.38\left(\mathrm{~s},-\mathrm{CH}_{2}-\right), 29.66\left(\mathrm{~m},-\mathrm{CH}_{2}-\right), 31.95\left(\mathrm{~s},-\mathrm{CH}_{2}-\right), 33.70\left(\mathrm{~s}, \mathrm{CH}_{2}\right)$, $44.58\left(\mathrm{~s}, \mathrm{CH}_{2} \mathrm{NCS}\right), 46.78\left(\mathrm{~m}, \mathrm{CH}_{2} \mathrm{NCS}, \mathrm{CH}_{2} \mathrm{~N}\right), 48.70\left(\mathrm{~s}, \mathrm{CH}_{2} \mathrm{~N}\right), 53.77(\mathrm{~s}, \mathrm{CH}), 68.67\left(\mathrm{~s}, \mathrm{CH}_{2} \mathrm{O}\right)$ $75.05(\mathrm{~s}, \mathrm{CHO}), 109.50\left(\mathrm{~s}, \mathrm{CO}_{2}\left(\mathrm{CH}_{3}\right)_{2}\right), 172.91(\mathrm{~s}, \mathrm{C}=\mathrm{O}), 183.26(\mathrm{~s}, \mathrm{C}=\mathrm{S})$. Anal. calcd. for $\mathrm{C}_{40} \mathrm{H}_{77} \mathrm{~N}_{5} \mathrm{O}_{5} \mathrm{~S}_{2}: \mathrm{C}, 62.22 ; \mathrm{H}, 10.05 ; \mathrm{N}, 9.07 ; \mathrm{S}, 6.30$. Found $\mathrm{C}, 62.17 ; \mathrm{H}, 10.17 ; \mathrm{N}, 8.94 ; \mathrm{S}, 7.07 . \mathrm{MS}$ $(\mathrm{ESI}, m / z)=794(\mathrm{M}+\mathrm{Na})^{+}, 770(\mathrm{M}-\mathrm{H})^{-}, 808(\mathrm{M}+\mathrm{Cl})^{+}$.

\section{(S)-2,7-bis[(2,2-dimethyl-1,3-dioxolan-4-yl)methylthiocarbamoylamino]-N,N-didodecyl-heptanamide}

(6b)

A solution of amine $4 \mathbf{b}(0.24 \mathrm{~g}, 0.5 \mathrm{mmol})$, and $N, N$-diisopropylethylamine $(0.44 \mathrm{~mL}, 2.5 \mathrm{mmol})$ in dichloromethane $(2 \mathrm{~mL})$ was stirred for 10 minutes before the addition of isothiocyanate $5(0.095 \mathrm{~g}$, $0.55 \mathrm{mmol})$. The reaction mixture was stirred overnight and evaporated under reduced pressure. Purification of the crude by SFC afforded $6 \mathbf{b}(0.23 \mathrm{~g}, 55 \%)$ as a colorless oil. ${ }^{1} \mathrm{H}$ NMR $\left(\mathrm{CDCl}_{3}\right) \delta$ (ppm) $0.87\left(\mathrm{t}, 6 \mathrm{H}, J=6.0 \mathrm{~Hz}, \mathrm{CH}_{3}\right), 1.25\left(\mathrm{~m}, 40 \mathrm{H},-\mathrm{CH}_{2}-\right), 1.32\left(\mathrm{~s}, 6 \mathrm{H},\left(\mathrm{CH}_{3}\right)_{2}\right), 1.34\left(\mathrm{~s}, 6 \mathrm{H},\left(\mathrm{CH}_{3}\right)_{2}\right)$, $1.44\left(\mathrm{~m}, 4 \mathrm{H},-\mathrm{CH}_{2}-\right), 1.68\left(\mathrm{~m}, 2 \mathrm{H},-\mathrm{CH}_{2}-\right), 3.21\left(\mathrm{~m}, 4 \mathrm{H}, \mathrm{CH}_{2} \mathrm{NCO}\right), 3.47\left(\mathrm{~m}, 2 \mathrm{H}, \mathrm{CH}_{2} \mathrm{NCS}\right) 3.70(\mathrm{~m}, 4 \mathrm{H}$, 
$\left.\mathrm{CH}_{2} \mathrm{NCS}\right), 4.05\left(\mathrm{~m}, 4 \mathrm{H}, \mathrm{CH}_{2} \mathrm{O}\right), 4.29(\mathrm{~m}, 4 \mathrm{H}, \mathrm{CHO}), 5.59(\mathrm{~m}, 1 \mathrm{H}, \mathrm{CH}),(\mathrm{m}, 2 \mathrm{H}, \mathrm{NH}), 7.86(\mathrm{~m}, 2 \mathrm{H}$, $\mathrm{NH}) .{ }^{13} \mathrm{C} \mathrm{NMR}(\mathrm{CDCl} 3) \delta(\mathrm{ppm}) 14.13\left(\mathrm{~s}, \mathrm{CH}_{3}\right), 22.73\left(\mathrm{~s},-\mathrm{CH}_{2}-\right), 25.27\left(\mathrm{~s},\left(\mathrm{CH}_{3}\right)_{2}\right), 26.87\left(\mathrm{~s},\left(\mathrm{CH}_{3}\right)_{2}\right)$, $27.71\left(\mathrm{~s},-\mathrm{CH}_{2}-\right), 28.71\left(\mathrm{~s},-\mathrm{CH}_{2}-\right), 29.07\left(\mathrm{~s},-\mathrm{CH}_{2}-\right), 29.68\left(\mathrm{~m},-\mathrm{CH}_{2}-\right), 31.98\left(\mathrm{~s},-\mathrm{CH}_{2}-\right), 33.68\left(\mathrm{~s}, \mathrm{CH}_{2}\right)$, 44.58 (s, $\left.\mathrm{CH}_{2} \mathrm{NCS}\right), 46.76$ (m, $\mathrm{CH}_{2} \mathrm{NCO}, \mathrm{CH}_{2} \mathrm{NCS}$ ), 48.63 (s, $\mathrm{CH}_{2} \mathrm{NCO}$ ), 53.77 (s, CH), 66.63 (s, $\left.\mathrm{CH}_{2} \mathrm{O}\right), 75.01(\mathrm{~s}, \mathrm{CHO}), 109.62\left(\mathrm{~s}, \mathrm{CO}_{2}\left(\mathrm{CH}_{3}\right)_{2}\right), 172.76(\mathrm{~s}, \mathrm{C}=\mathrm{O}), 183.23(\mathrm{~s}, \mathrm{C}=\mathrm{S})$. Anal. calcd. for $\mathrm{C}_{44} \mathrm{H}_{85} \mathrm{~N}_{5} \mathrm{O}_{5} \mathrm{~S}_{2}: \mathrm{C}, 63.80 ; \mathrm{H}, 10.34 ; \mathrm{N}, 8.45 ; \mathrm{S}, 7.74$. Found $\mathrm{C}, 63.94 ; \mathrm{H}, 10.51 ; \mathrm{N}, 7.80 ; \mathrm{S}, 7.46 . \mathrm{MS}$ $(\mathrm{ESI}, m / z)=850(\mathrm{M}+\mathrm{Na})^{+}, 828(\mathrm{M}+\mathrm{Cl})^{-}$.

(S)-2,7-bis[(2,2-dimethyl-1,3-dioxolan-4-yl)methylthiocarbamoylamino]-N,N-ditetradecylheptanamide (6c).

A solution of amine $4 \mathbf{c}(0.12 \mathrm{~g}, 0.22 \mathrm{mmol})$, and $N, N$-diisopropylethylamine $(0.3 \mathrm{~mL}, 2.2 \mathrm{mmol})$ in dichloromethane $(1.5 \mathrm{~mL})$ was stirred for $10 \mathrm{mn}$ before the addition of isothiocyanate $5(0.1 \mathrm{~g}, 0.55$ mmol). The reaction mixture was stirred overnight and evaporated under reduced pressure. Purification of the crude by SFC afforded $6 \mathbf{c}(75 \mathrm{mg}, 38 \%)$ as a colorless oil. ${ }^{1} \mathrm{H} \mathrm{NMR}\left(\mathrm{CDCl}_{3}\right) \delta(\mathrm{ppm}) 0.87(\mathrm{t}, 6 \mathrm{H}$, $\left.J=6.0 \mathrm{~Hz}, \mathrm{CH}_{3}\right), 1.25\left(\mathrm{~m}, 44 \mathrm{H},-\mathrm{CH}_{2}-\right), 1.33\left(\mathrm{~s}, 6 \mathrm{H},\left(\mathrm{CH}_{3}\right)_{2}\right), 1.37\left(\mathrm{~s}, 6 \mathrm{H},\left(\mathrm{CH}_{3}\right)_{2}\right), 1.44\left(\mathrm{~m}, 4 \mathrm{H},-\mathrm{CH}_{2}-\right)$, $1.67\left(\mathrm{~m}, 2 \mathrm{H}, \mathrm{CH}_{2}\right), 3.20\left(\mathrm{~m}, 4 \mathrm{H}, \mathrm{CH}_{2} \mathrm{NCO}\right), 3.45$ (m, 2H, $\left.\mathrm{CH}_{2} \mathrm{NCS}\right), 3.69$ (m, 4H, $\mathrm{CH}_{2} \mathrm{NCS}_{\text {) }}, 4.05$ (m, 4H, $\left.\mathrm{CH}_{2} \mathrm{O}\right), 4.29(\mathrm{~m}, 4 \mathrm{H}, \mathrm{CHO}), 5.59(\mathrm{~m}, 1 \mathrm{H}, \mathrm{CH}), 6.85(\mathrm{~m}, 2 \mathrm{H}, \mathrm{NH}), 7.80(\mathrm{~m}, 2 \mathrm{H}, \mathrm{NH}) .{ }^{13} \mathrm{C}$ NMR $\left(\mathrm{CDCl}_{3}\right) \delta(\mathrm{ppm}) 14.15\left(\mathrm{~s}, \mathrm{CH}_{3}\right), 22.74\left(\mathrm{~m},-\mathrm{CH}_{2}-\right), 25.26\left(\mathrm{~s},\left(\mathrm{CH}_{3}\right)_{2}\right), 27.06\left(\mathrm{~s},\left(\mathrm{CH}_{3}\right)_{2}\right), 27.15\left(\mathrm{~s},-\mathrm{CH}_{2}-\right)$, $28.69\left(\mathrm{~s},-\mathrm{CH}_{2}-\right), 29.07\left(\mathrm{~s},-\mathrm{CH}_{2}-\right), 29.68\left(\mathrm{~m},-\mathrm{CH}_{2}-\right), 31.97\left(\mathrm{~s},-\mathrm{CH}_{2}-\right), 33.69\left(\mathrm{~s}, \mathrm{CH}_{2}\right), 44.54(\mathrm{~s}$, $\left.\mathrm{CH}_{2} \mathrm{NCS}\right), 46.74$ (m, $\left.\mathrm{CH}_{2} \mathrm{NCO}, \mathrm{CH}_{2} \mathrm{NCS}\right), 46.63$ (s, $\left.\mathrm{CH}_{2} \mathrm{NCO}\right), 53.74$ (s, CH), $66.61\left(\mathrm{~s}, \mathrm{CH}_{2} \mathrm{O}\right), 75.01$ (s, CHO), $109.60\left(\mathrm{~s}, \mathrm{CO}_{2}\left(\mathrm{CH}_{3}\right)_{2}\right), 172.79(\mathrm{~s}, \mathrm{C}=\mathrm{O}), 183.19(\mathrm{~s}, \mathrm{C}=\mathrm{S}) . \mathrm{MS}(\mathrm{ESI}, \mathrm{m} / \mathrm{z}) 907(\mathrm{M}+\mathrm{Na})^{+}, 931$ $(\mathrm{M}+\mathrm{HCOO})^{-}$. Anal. calcd. for $\mathrm{C}_{48} \mathrm{H}_{93} \mathrm{~N}_{5} \mathrm{O}_{5} \mathrm{~S}_{2}: \mathrm{C}, 65.19 ; \mathrm{H}, 10.60 ; \mathrm{N}, 7.92 ; \mathrm{S}, 7.25$. Found C, 65.18; H, 10.66; N, 7.21; S, 6.58. HR-ESMS calcd. for $\mathrm{C}_{48} \mathrm{H}_{93} \mathrm{~N}_{5} \mathrm{O}_{5} \mathrm{NaS}_{2}$ : 906.6516. Found 906.6498.

\section{Liposome preparation.}

Ethanolic injection method: Lipopolythiourea and DPPC were dissolved in ethanol and were added dropwise to 10 volumes of water under vigorous agitation. The mixture was stirred overnight and then 
evaporated under reduced pressure at room temperature to obtain a fairly concentrated solution of liposomes.

As an example, compound $6 \mathrm{c}(1.77 \mathrm{mg}, 2 \mu \mathrm{mol})$ and DPPC $(1.47 \mathrm{mg}, 2 \mu \mathrm{mol})$ were dissolved in 300 $\mu \mathrm{L}$ ethanol. This solution was added dropwise into $3 \mathrm{~mL}$ of stirred filtered water. The mixture was stirred overnight then evaporated under reduced pressure at RT to obtain a clear suspension of $6 \mathbf{c} /$ DPPC (0.380 mL, $10.5 \mathrm{mM}$ total lipids).

Film hydration method: Lipopolythiourea and DPPC were dissolved in chloroform. The solvent was evaporated slowly under vacuum to obtain a thin film on the glass. Water was then added to hydrate the lipids and obtain a fairly concentrated solution of liposomes.

As an example, compound 6c $(4.0 \mathrm{mg}, 4.5 \mu \mathrm{mol})$ and DPPC (3.2 $\mathrm{mg}, 4.3 \mu \mathrm{mol})$ were dissolved in chloroform $(500 \mu \mathrm{L})$. The solvent was evaporated slowly under vacuum to obtain a thin film on the glass. Water $(430 \mu \mathrm{L})$ was then added to hydrate the lipids and obtain a solution of liposomes $(20 \mathrm{mM}$ total lipids).

Size measurement. Particle diameter was determined by dynamic light scattering on a Zeta Sizer NanoSeries Malvern (Malvern Instruments, France). Concentration of the lipids $=0.1 \mathrm{mM}$ in $\mathrm{H}_{2} \mathrm{O}$, mean value of 3 runs are given ( 1 min equilibration, 3 min run).

Preparation of plasmid DNA. pVax2 is a derivative of the commercial plasmid pVax1 (InVitrogen). pVaxl was digested with the restriction enzymes HincII and BamHI to excise the promoter. The plasmid was then blunted with the Klenow fragment and dephosphorylated with alkaline phosphatase. pCMVbeta (Clontech) was digested with EcoR1 and BamHI to excise the CMV promoter. The CMV promoter was blunted with Klenow enzyme and ligated into the blunted pVax1 to give pVax2. The plasmid pXL3031 was digested with EcoRI and BamHI, and then treated with the Klenow fragment to produce a blunted fragment containing the luciferase cDNA. This fragment was ligated into pVax2 after EcoRVdigestion and phosphatase alkaline dephosphorylation to give pVax2-Luc. 
Preparation of LPT/DNA complexes. Plasmid DNA (pVax2-luc, $100 \mu \mathrm{L}, 0.02 \mathrm{~g} / \mathrm{L}$ in $\mathrm{H}_{2} \mathrm{O}$ ) prepared using the procedure above, was added dropwise with constant vortexing to various amounts of LPT/DPPC liposomes (in $100 \mu \mathrm{L} \mathrm{H}_{2} \mathrm{O}$ ) at RT. TU/P indicates the ratio in nmol of thiourea function (2 per lipid) versus DNA phosphates. Cationic lipoplexes were formed in the same way from RPR209120/DOPE liposomes (1/1, hydration film method, $4 \mathrm{nmol}$ in $100 \mu \mathrm{L} \mathrm{NaCl} 150 \mathrm{mM})$ mixed with plasmid DNA at ratio $\mathrm{N} / \mathrm{P}=8(0.5 \mu \mathrm{g}$ in $100 \mu \mathrm{L} \mathrm{NaCl} 150 \mathrm{mM})$. PEI/DNA polyplexes were prepared from PEI $(1 \mu \mathrm{g}$ in $100 \mu \mathrm{L}$ glucose $5 \%)$ mixed with plasmid DNA $(0.5 \mu \mathrm{g}$ in $100 \mu \mathrm{L}$ glucose $5 \%$ ) at a $\mathrm{N} / \mathrm{P}$ ratio $=15$

Gel retardation experiments. Complexes were prepared as described above with liposomes made by ethanolic injection $(20 \mu \mathrm{L})$ and $5 \mu \mathrm{L}$ of bromophenol blue were added. The mixture was loaded on a 0.8 $\%$ agarose gel in TBE buffer (1M Tris, $0.9 \mathrm{M}$ boric acid, $0.01 \mathrm{M}$ EDTA) at $80 \mathrm{~V} / \mathrm{cm}$. DNA was revealed with ethidium bromide and visualized under UV light.

DNA protection. $20 \mu \mathrm{L}$ of culture medium (MEM with $10 \%$ or $50 \%$ murine fresh serum) were added on $20 \mu \mathrm{L}$ of LPT/DPPC/DNA complexes $(0.1 \mathrm{~g} / \mathrm{L}$ DNA, prepared by ethanolic injection) or of cationic lipoplexes made of RPR209120 (0.1 g/L DNA). Samples were incubated at 37 C. After 6h, 10 $\mu \mathrm{L}$ of samples were frozen at $-20^{\circ} \mathrm{C}$. After $24 \mathrm{~h}$, all the samples were replaced at RT. SDS $2 \%(5 \mu \mathrm{L})$, EDTA $(2 \mu \mathrm{L}, 0.5 \mathrm{M})$ and bromophenol blue $(3 \mu \mathrm{L})$ were added on each sample $(10 \mu \mathrm{L})$. The mixture was loaded on agarose gel $1 \%$ containing $0.05 \% \mathrm{SDS}$ at $80 \mathrm{~V} / \mathrm{cm}$. After $24 \mathrm{~h}$ washing in water, DNA was revealed with ethidium bromide and visualized under UV light.

Transfection method. B16 murine cells were grown into DMEM supplemented with L-glutamin (29.2 mg/mL), penicillin (50 units/mL), streptomycin (50 units/mL) and 10\% fetal bovine serum. One day before transfection, cells were treated by trypsin and deposed into 24-wells plates (45000 cells/well) and incubated $24 \mathrm{~h}$ at $37^{\circ} \mathrm{C} .100 \mu \mathrm{L}$ of LPT/DNA complexes (prepared by ethanolic injection), $100 \mu \mathrm{L}$ of RPR209120/DOPE/DNA (prepared as above, ratio N/P = 8) and PEI/DNA polyplexes (prepared as above, ratio $\mathrm{N} / \mathrm{P}=15$ ), all formulations corresponding to $0.5 \mu \mathrm{g}$ DNA, were loaded on each well and the 
plates were incubated at $37^{\circ} \mathrm{C}$ for $48 \mathrm{~h}$. Then the cells were washed twice with PBS and treated with $200 \mu \mathrm{L}$ of a passive lysis buffer (Promega). After $15 \mathrm{~min}$, the cells were centrifuged for $5 \mathrm{~min}$ at 12000 r/min. Supernatant $(10 \mu \mathrm{L})$ and iodoacetamide $(10 \mu \mathrm{L})$ were added to a 96-well plate which was incubated at $37^{\circ} \mathrm{C}$ for $1 \mathrm{~h}$. Protein quantification was performed with the BCA protein assay KIT (PIERCE) and reported to BSA taken as a reference curve. Luciferase activity was quantified using a commercial kit Luciferase assay system (PROMEGA). On $10 \mu \mathrm{L}$ of the lysed cells, $50 \mu \mathrm{L}$ of the luciferase substrate was injected via an injector and the absorbance was read immediately at $563 \mathrm{~nm}$ on a Wallac Victor2 1420 Multilabel Counter Perkin Elmer.

Cytotoxicity on B16 murine cells. Murine B16 melanoma cells were grown in DMEM containing $2 \mathrm{mM}$ L-glutamine, $10 \%$ fetal bovine serum, $100 \mathrm{U} / \mathrm{mL}$ penicillin, and $100 \mu \mathrm{g} / \mathrm{mL}$ streptomycin $\left(37^{\circ} \mathrm{C}\right.$, $5 \% \mathrm{CO}_{2}$ ). Exponentially growing B16 cells were plated onto 96-well plates at 5000 cells per well in $100 \mu \mathrm{L}$ of culture medium. Twenty-four hours after plating, $100 \mu \mathrm{L}$ of medium containing the compound of interest (final concentrations ranging from $1.56 \mu \mathrm{g} / \mathrm{mL}$ to $100 \mu \mathrm{g} / \mathrm{mL}$, in 2 -fold dilutions) was added to the wells (in triplicate) containing the cells and incubated for $48 \mathrm{~h}$ at $37{ }^{\circ} \mathrm{C}$ and $5 \% \mathrm{CO}_{2}$. After the $48 \mathrm{~h}$ exposure period to the test compounds, cell viability was assayed using the MTT test (27) and absorbance was read at $562 \mathrm{~nm}$ in a microplate reader (BioKinetics Reader, EL340). Appropriate controls with DMEM only and MTT were run to substract background absorbance. Results are presented as percent of controls cells. The concentration of compound that inhibited cell viability by $50 \%$ (inhibitory concentration for $50 \%$ of cells, or $\mathrm{IC}_{\text {so }}$ ) was determined using the GraphPad Prism software. Results are presented as means \pm SEM of 6 independent experiments each run in triplicate.

In vivo acute toxicity test. 6c/DPPC particles $(0.75 \mu \mathrm{mol}, 200 \mu \mathrm{L})$ were injected into Swiss mice tail vein ( 3 mice for the sample, 3 mice control). Animals were observed daily over 16 days about their weight, behavior pattern, skin and fur modifications and somatomotor activity (28). The dose was considered as toxic if the weight was lower than $80 \%$ of the controlled mice. 
Intratumoral injection. 6c/DPPC/DNA $(40 \mu \mathrm{L}, 10 \mu \mathrm{g}$ DNA, $40 \mathrm{TU} / \mathrm{P}, \mathrm{TU} / \mathrm{P}=$ mol thiourea functions/mol DNA phosphate group) and RPR209120/DOPE/DNA (prepared as above, ratio N/P =6) were injected in 3LL tumors of 3 mice C57BL $\backslash 6$ bearing 3LL tumors. Mice were sacrificed $24 \mathrm{~h}$ after injection, then tumors were removed, weighed, crushed in $1 \mathrm{~mL}$ lysis buffer, and centrifuged during 10 minutes $\left(12000 \mathrm{rpm}, 4^{\circ} \mathrm{C}\right)$. The supernatant $(50 \mu \mathrm{L})$ was loaded on a 96-well plates and luciferase activity was quantified using a commercial kit (Protein Assay). The absorbance was read at $563 \mathrm{~nm}$ on a Wallac Victor2 1420 Multilabel Counter Perkin Elmer.

\section{Biodistribution study.}

Experiments were conducted following NIH recommendation for animal experimentation. Rhodamine-labeled 6c/DPPC/DNA complexes $(200 \mu \mathrm{L}, 11 \mu \mathrm{g}$ DNA, $40 \mathrm{TU} / \mathrm{P})$ were injected in tail vein of five mice C57BL $\backslash 6$ bearing 3LL tumors. Blood was collected by cardiac puncture after $2 \mathrm{~h}$, and mice were euthanized at the end of the sample taking. In the distribution study, liver, lungs, spleen, and tumors were removed, weighed, and homogenized in $\mathrm{pH} 7.4$ phosphate-buffered saline (PBS, 5mL/g tissue). Rhodamine-labeled lipids were extracted as previously described (29) from $100 \mu \mathrm{L}$ of blood or tissue homogenates with $3 \mathrm{~mL}$ of $\mathrm{CHCl}_{3}-\mathrm{CH}_{3} \mathrm{OH}(1: 1, \mathrm{v} / \mathrm{v})$ by vigorous mixing during 30 min for blood and $40 \mathrm{~min}$ for tissue homogenates followed by centrifugation (3000 rpm, $10 \mathrm{~min})$. The fluorescence intensity corresponding to rhodamine was assayed on the supernatant with a fluorospectrophotometer (Victor, Perkin Elmer_Wallac multiplate reader, $\lambda_{\text {exc }} 530 \mathrm{~nm}, \lambda_{\mathrm{em}} 570 \mathrm{~nm}$ ). The amount of complexes in the blood or tissue homogenates was evaluated with a calibration curve of the initial $6 \mathbf{c} / \mathrm{DPPC} / \mathrm{DNA}$ complexes containing $0.5 \%$ LPT-rhodamine and expressed as the remaining percentage of injected dose.

\section{RESULTS}

\section{Chemistry.}

The lipopolythioureas were prepared as shown in Scheme 1. The synthesis started from boc lysine 2 that reacted with dialkylamine 1a, 1b and 1c to yield dialkylamide 3a-c (45 to $67 \%$ ). Boc removal 
using TFA in dichloromethane led to diamines 4a-c in good yields (68, 100, 100\% respectively). Treatment of the diamine with isothiocyanate 5 afforded the protected thioureas $(6 \mathbf{6} 83 \%, 6 \mathbf{b} 55 \%, 6 \mathbf{c}$ $38 \%$ ). Attempts to remove the acetal group failed, giving only the starting alkylamine 1 . This result suggests a rearrangement leading to a cyclic thiourea under protic catalysis, since such cyclic compounds have been described in literature (30). However, despite our efforts we were unable to identify such a compound.

Scheme 1

\section{Formulation study and DNA association.}

The three compounds prepared $\mathbf{6 a}, \mathbf{6 b}$ and $\mathbf{6 c}$ exhibit the same thiourea headgroup and differentiate themselves by their lipidic length, varying from 10 to 12 to 14 carbons, respectively. First, we tried to evaluate if their hydrophilic/lipophilic balance would allow forming homogeneous particles. This was achieved thanks to the adjunction of dipalmytoyl-phosphatidylcholine (DPPC) as a ratio 1 to 1 with the polythiourea lipid. Particle diameter is given in Table 1. The diameter was slightly higher for $\mathbf{6 c}$ as compared to $\mathbf{6 b}$ and $\mathbf{6 a}$. Also, the suspension formed was more homogeneous with compound $\mathbf{6 c}$, as shown by the polydispersity index. This might suggest a better interaction of compound $\mathbf{6 c}$ with DPPC due to its longer chain length.

\begin{tabular}{|c|c|c|c|c|c|c|c|}
\hline LPT & $\begin{array}{c}\text { Chain } \\
\text { length }\end{array}$ & $\begin{array}{c}\text { Formulation } \\
\text { (ethanolic injection) }\end{array}$ & Diameter (nm) & PDI & $\begin{array}{c}\text { TU/P for } \\
\text { DNA } \\
\text { association }\end{array}$ & $\begin{array}{c}\text { LPT/DNA } \\
\text { Diameter } \\
\text { (nm) }\end{array}$ & PDI \\
\hline $\mathbf{6 a}$ & $10 \mathrm{C}$ & $\mathbf{6 a} /$ DPPC $1 / 1$ & $76.5 \pm 11$ & 0.337 & 40 & $96 \pm 2$ & 0.253 \\
\hline $\mathbf{6 b}$ & $12 \mathrm{C}$ & $\mathbf{6 b} /$ DPPC $1 / 1$ & $102 \pm 8$ & 0.329 & 20 & $122 \pm 6$ & 0.165 \\
\hline $\mathbf{6 c}$ & $14 \mathrm{C}$ & $\mathbf{6 c} /$ DPPC $1 / 1$ & $141 \pm 50$ & 0.239 & 10 & $164 \pm 3$ & 0.115 \\
\hline
\end{tabular}

Table 1. Formulation and DNA association with lipopolythiourea $\mathbf{6 a}, \mathbf{6 b}$ and $\mathbf{6 c}$. Diameter is given as a mean of 3 values. PDI: polydispersity index. TU/P for DNA association is the number of thiourea/ DNA phosphate ratio needed to retain DNA on the wells in agarose gel. The diameters of LPT/DNA complexes are given at the ratio needed for the association. 
Addition of DNA to these particles induced a slight increase in particle diameter. LPT/DNA interaction was evidenced by this size increase along with gel electrophoresis. We relate in Table 1 the ratio between the thiourea and the phosphate functions (TU/P) needed to fully retain DNA on the wells of an agarose gel. As can be seen, all LPT were able to complex the plasmid. Moreover, the longer the lipid chain, the less amount of LPT was necessary to obtain a full interaction with DNA, reaching a minimum for $6 \mathrm{c}(10 \mathrm{TU} / \mathrm{P})$. This could be linked to the suspension homogeneity obtained when DPPC was mixed with lipid 6c.

\section{Lipoplex sensitivity to serum.}

The complexes formed between LPT and DNA have been submitted to a treatment in fresh mice serum at $37^{\circ} \mathrm{C}$ for $6 \mathrm{~h}$ and $24 \mathrm{~h}$, and then loaded on a denaturing agarose gel. As observed on Figure 1, free plasmid DNA was partially degraded after $6 \mathrm{~h}$, and fully degraded after $24 \mathrm{~h}$ under these conditions, whereas complexed DNA was still intact. As regard to the technique sensitivity, no difference between the three lipids could be detected. These results confirm that the interaction occurring between LPT and DNA is strong enough to protect plasmid DNA from degradation in the presence of serum.

Figure 1

\section{Transfection efficiency in vitro.}

Compounds $\mathbf{6 a}, \mathbf{6 b}$ and $\mathbf{6 c}$ were further evaluated for their transfection activity. Since the aim of these nonelectrostatic systems is to improve the in vivo gene delivery, we carried out in vitro studies as preliminary tests for in vivo experiments. Thus, we performed the experiments in the presence of serum with particles of nanometric size. Two different TU/P ratios were evaluated for the three different formulations and compared to the cationic lipid (RPR209120) (31) and the cationic polymer PEI (32) (Figure 2) mixed with DNA. 
Figure 2

As can be seen on Figure 3, transfection efficiency was dependent on the LPT used. Hence, higher transfection activity was obtained when increasing the lipid length from 10 to 14 carbons, from 6a to $6 \mathbf{c}$ respectively. Moreover, increasing the amount of LPT, from $\mathrm{TU} / \mathrm{P}=20$ to 40 , also led to improved transfection. However, for higher LPT amount we observed a decrease of the protein amount, suggesting some cytotoxicity.

\section{Cytotoxicity.}

In order to reduce the cytotoxicity, we have studied the effect of different formulation protocols. Particles mentioned in the previous experiments were formulated via an ethanolic injection protocol (33). We also prepared LPT particles via the film hydration method (34). After preparation, we submitted the cells to a MTT test and compared the $\mathrm{IC}_{50}$ of the two different formulations. As can be seen on Figure 4, the cytotoxicity $\mathrm{IC}_{50}$ obtained for compound $\mathbf{6 a}$ formulated via an injection method was $15 \mu \mathrm{M}$, while no toxicity could be measured when the same compound was formulated via the hydration method. This significant reduction of toxicity might be due to the reduction of the number of thiourea presented at the surface of the liposome since multilamellar vesicles (MLV) are formed by the hydration method, whereas unilamellar vesicles (SUV) are obtained by ethanolic injection (35). The in vitro efficiency of theses complexes was also evaluated and, showed slightly the same level of transfection as compared to the previous one $(9900 \mathrm{RLU} / \mu \mathrm{g}$ protein for a ratio $\mathrm{TU} / \mathrm{P}=20)$. This good tolerance prompted us to use the hydration method for the following in vivo studies

Figure 4

According to the in vitro cytotoxicity results, we evaluated the in vivo toxicity of the least toxic and most efficient formulation: $\mathbf{6 c} / \mathrm{DPPC}$, prepared by the hydration film method. The formulation was 
injected once at $\mathrm{t}=0$, then the mice weight, as well as different toxicity signs such as locomotion, behaviour, changes in skin and fur, were followed over 2 weeks. The formulations were considered as nontoxic if the weight loss was lower than $20 \%$ as compared to the controlled mice. The formulation 6c/DPPC prepared via the hydration method displayed an excellent tolerance, since the somatomotor activity, the behavior pattern and skin and fur characteristics were unchanged as assayed over a period of 16 days. The weight also remained stable from $98.6 \%$ at day 2 , to $97.6 \%$ at day 5 to $98.65 \%$ of the controls at day 16.

\section{In vivo properties.}

The absence of toxicity for the formulation $\mathbf{6 c} / \mathrm{DPPC}$ prompted us to investigate further the in vivo behavior of these particles.

First, we evaluated the transfection activity of the formulation 6c/DPPC after intratumoral injection, and compared it (36) to the lipoplexes composed of the lipopolyamine RPR209120. We did not observe a significant difference between the two formulations; both were able to induce a luciferase activity $24 \mathrm{~h}$ post-injection.

Biodistribution of $\mathbf{6 c} / \mathrm{DPPC}$ was evaluated by introduction of a fluorescent lipid marker (37) and compared to a cationic formulation of the lipopolyamine RPR209120/DOPE prepared via an identical hydration film procedure. $2 \mathrm{~h}$ after injection, different organs were removed and assessed for their fluorescence content. As shown on Figure 5, a significative gain of a factor 4 to $5(\mathrm{p}<0.01)$ was obtained in the blood circulation particles using the neutral $\mathbf{6 c} / \mathrm{DPPC}$ formulation as compared to the cationic one. Despite this higher circulation time in the blood, no significant difference was found in tumor localization. Furthermore, an important difference was observed in the lung $(\mathrm{p}<0.01)$. Nonspecific accumulation of the particles in the lung, which has often been reported for cationic particles (38), did not occur in the case of the LPT formulation. A similar amount was found in the liver for the two formulations, which was expected as elimination by Kupffer cells is mostly related to the particle size (39). 
Figure 5

\section{DISCUSSION}

The above data show that the described lysine derived polythiourea mixed with DPPC are able to associate to plasmid DNA, to protect it from degradation in the presence of serum and to induce gene expression in cultured cells. Transfection efficiency was shown to be chain length dependent, the lipid 6c bearing the longer chain exhibiting the highest transfection activity. Some results have shown that a shorter chain was more appropriate for optimized transfection (40). We had also observed that with a lipopolythiourea bearing a serinol headgroup (20). Figure 6 represents the comparison of the in vitro results mediated by the two lipopolythiourea family. It shows that, indeed, the transfection level is reversed between the two LPT family, the shorter chain is preferable for the serinol thiourea lipids, shown on figure 7 , while the longer chain is preferable for the lysine thiourea lipids. That could be related to the improved hydrophilic/lipophilic balance in the lipid. In this work, the hydrophobic nature of the LPT required the use of a colipid, and obviously the colipid effect is of great importance as was previously reported (41). Mixing LPT with DPPC (bearing 16 carbons in the alkyl chain) might be more appropriate for the LPT $6 \mathbf{c}$, inducing improved lipid packing as the chain length of the LPT increases from 10 to 14 carbons. Indeed, suspension polydispersity decreased from the formulation $6 \mathbf{6} / \mathrm{DPPC}$ to 6c/DPPC. The shorter chain LPT might create disorder in the lipid bilayer eventually leading to unstable particles (42). Alternatively, we can hypothesize that the bulky and unsymmetrical LPT headgroup might also interfere with the lipid packing and that a stronger hydrophobic interaction between LPT and the colipid might counterbalance the headgroup interference.

Figure 6 
Despite its structure, this lysine-based uncharged headgroup allowed for efficient interaction with DNA at a LPT/DNA ratio similar to the one previously obtained for LPT bearing a serinol headgroup $(\mathrm{TU} / \mathrm{P}=15)$. This ratio was the lowest for the formulation $\mathbf{6 c} / \mathrm{DPPC}$, as compared to $\mathbf{6 b}$ and $\mathbf{6 a}$, which is probably related to the more homogeneous structure formed between lipid $\mathbf{6 c}$ and DPPC.

The most efficient transfection obtained with lipid $\mathbf{6 c}$ was higher than the previously reported serinol LPT at the ratio used (20) (Figure 6) and comparable to that of cationic formulations in the presence of serum. This is of particular interest considering that LPT formulations exhibit no positive charges and might interact less favorably with the anionic cell membranes. The absence of cationic charges was also confirmed by the in vivo improved kinetic properties of LPT/DNA complexes, which avoided nonspecific accumulation in the lung and blood circulation. However, this "stealth advantage" did not enhance passive accumulation in our tumor model in opposite to the proposed enhanced permeability and retention effect (43). We have already observed this lack of passive accumulation on 3LL tumors after chemical passivation of the cationic charges of lipoplexes (9). This points the use of a targeting ligand at the surface of these DNA/lipid particles in order to deliver DNA at a proper site, especially as this strategy has already been validated in the case of lipopolythiourea (19).

\section{Figure 7}

In conclusion, we described here a new noncationic transfecting agents bearing a polythiourea moiety. From this and previous results, we can deduce that a wide range of geometry and terminus allowed LPT/DNA interaction. With the present compound $\mathbf{6 c}$, this association was found to be strong enough to protect plasmid in the presence of serum and to obtain in vitro efficient cell transfection, comparative to that obtained with cationic lipids. Moreover, we could find a nontoxic window for in vivo use of these complexes. Intratumoral injection of LPT/DNA complexes showed that in vivo transfection ability and biodistribution were favorably improved as compared to cationic complexes. Finally we have found in our previous studies that the size of the hydrophobic anchor seemed to be one of the factor controlling 
the physico-chemical and the transfecting properties of the LPTU. Structural comparison between 6a-6c and Ia-Ic (Figure 7) shows two main differences between them. First the lack of a linker, second the presence of a 1,5-diamine instead of a 1,3-diamine for the headgroups. This suggests that a larger diamino chain would lead to better phosphate/thiourea interactions. This hypothesis is supported by the study of Bianco et al. (44) that demonstrate strong thiourea/phosphate interaction for thiourea-linked glycooligomers (Figure 7, Compound VI). In these molecules the two thioureas are in a 1,4 relationships favoring their participation in bidentate hydrogen-bond interactions with oxoanions. Compounds III, IV and V (Figure 7) possess also a 1,5 relationship between the two thioureas (19). However their lack of transfecting properties is probably due to their hydrophobicity. In addition, the presence of the acetal ring adds a constraint that could diminished the strength of hydrogen bonds. New models have been synthesized and are now under investigation to verify these hypotheses.

ACKNOWLEDGMENT: This work was financially supported by INSERM, CNRS, MNERT, the Région Ile de France (SESAME, CPER). J.L. thanks the MNERT for a doctoral fellowship.

\section{REFERENCES}


(1) Miller, A. D. (1998) Cationic liposomes for gene therapy. Angew. Chem. Int. Ed. 37, 1768-1785.

(2) Verma, I. M., Weitzman, M. D. (2005) Gene therapy: twenty-first century medicine. Annu. Rev. Biochem. 74, 711-738.

(3) Simberg, D., Weisman, S., Talmon, Y., Barenholz, Y. (2004) DOTAP (and other cationic lipids): chemistry, biophysics, and transfection. Crit. Rev. Ther. Drug Carrier Syst. 21, 257-317.

(4) Pack, D. W., Hoffman, A. S., Pun, S., Stayton, P. S. (2005) Design and development of polymers for gene delivery. Nature Rev. Drug Discovery 4, 581-593.

(5) Ewert, K., Slack, N. L., Ahmad, A., Evans, H. M., Lin, A. J., Samuel, C. E., Safinya, C. R. (2004) Cationic lipid-DNA complexes for gene therapy: understanding the relationship between complex structure and gene delivery pathways at the molecular level. Curr. Med. Chem. 11, 133-49.

(6) Tandia, B. M., Vandenbranden, M., Wattiez, R., Lakhdar, Z., Ruysschaert. J. M., Elouahabi, A. (2003) Identification of human plasma proteins that bind to cationic lipid/DNA complex and analysis of their effects on transfection efficiency: implications for intravenous gene transfer. Mol. Ther. 8, 264273.

(7) Escriou, V., Ciolina, C., Lacroix, F., Byk, G., Scherman, D., Wils, P. (1998) Cationic lipidmediated gene transfer: effect of serum on cellular uptake and intracellular fate of lipopolyamine/DNA complexes. Biochim. Biophys. Acta 1368, 276-288

(8) Eliyahu, H., Servel, N., Domb, A., Barenholz, Y. (2002) Lipoplex-induced hemagglutination: potential involvement in intravenous gene delivery. Gene Ther. 9, 850-858. 
(9) Thompson, B., Mignet, N., Hofland, H., Lamons, D., Seguin, J., Nicolazzi, C., de la Figuera, N., Kuen, R. L., Meng, X. Y., Scherman, D., Bessodes, M. (2005) Neutral postgrafted collloidal particles for gene delivery. Bioconjugate Chem. 16, 608-14.

(10) Mignet, N., Gregoriadis, G. (2006) Liposome technology $3^{\text {rd }}$ ed. London, vol 2, ch.16, in press.

(11) Faneca, H., Simoes, S., Pedroso de Lima, M. C., (2004) Association of albumin or protamine to lipoplexes: enhancement of transfection and resistance to serum. J. Med.Chem. 6, 681-692.

(12) Aoyama, Y., Kanamori, T., Nakai, T., Sasaki, T., Horiuchi, S., Sando, S., Niidome, T. (2003) Artificial viruses and their application to gene delivery. Size-controlled gene coating with glycocluster nanoparticles. J. Am. Chem. Soc. 125, 3455-7.

(13) Arignon, J., Prata, C. A., Grinstaff, M. W., Barthelemy, P. (2005) Nucleic acid complexing glycosyl nucleoside-based amphiphiles. Bioconjug. Chem. 16, 864-872.

(14) Nakai, T.; Kanamori, T.; Sando, S and Aoyama, Y. (2003) Remarkably Size-Regulated Cell Invasion by Artificial Viruses. Saccharide-Dependent Self-Aggregation of Glycoviruses and Its Consequences in Glycoviral Gene Delivery. J. Am. Chem. Soc. 125, 8465-8475.

(15) Chabaud, P., Camblo, M., Payet, D., Serin, G., Moreau, L., Barthelemy, P., Grinstaff, M. W. (2006) Cationic nucleoside lipids for gene delivery. Bioconjug. Chem. 17, 466-472.

(16) Bailey, A., Sullivan, S. M. (2000) Efficient encapsulation of DNA plasmids in small neutral liposomes induced by ethanol and calcium, Biochim. Biophys. Acta, 1468, 239-252.

(17) Roux, D., Chenevier, D., Pott, T., Navailles, L., Regev, O., Mondain Monval, O. (2004) Conception and realization of a non-viral and non-cationic DNA vector, Curr. Med. Chem., 11, 2, 169177. 
(18) Tranchant, I., Mignet, N., Crozat, E., Leblond, J., Girard, C., Scherman, D., Herscovici, J. (2004) DNA complexing lipopolythiourea. Bioconjug Chem. 15, 1342-8.

(19) Leblond, J., Mignet, N., Leseurre, L., Largeau, C., Bessodes, M., Scherman, D., Herscovici, J., (2006) Design, Synthesis, and Evaluation of Enhanced DNA Binding New Lipopolythioureas Bioconjug. Chem. 17, 1200-1208.

(20) Leblond, J., Mignet, N., Largeau, C., Spanedda, M-V., Seguin, J., Scherman, D., Herscovici, J., (2007) Lipopolythioureas: a new non-cationic system for gene transfer. Bioconjug Chem. 18, 484-493.

(21) Benito, J.M., Gomez-Marcia, M., Jimenez Blanco, J.L., Ortiz Mellet, C., Garcia Fernandez, J.M. (2001) Carbohydrate-based receptors with multiple thiourea binding sites. Multipoint hydrogen bond recognition of dicarboxylates and monosaccharides. J. Org. Chem. 66, 1366-72.

(22) Takemoto Y. (2005) Recognition and activation by ureas and thioureas: stereoselective reactions using ureas and thioureas as hydrogen-bonding donors. Org. Biomol. Chem. 3, 4299-306.

(23) Gómez, D.E., Fabbrizzi, L., Licchelli, M., Monzani, E. (2005) Urea vs. thiourea in anion recognition. Org. Biomol. Chem. 3, 1495-500.

(24) Bühlmann, P., Nishizawa, S., Xiao, K.P., Umezawa, Y. (1997) Strong hydrogen-bond mediated complexation of $\mathrm{H}_{2} \mathrm{PO}_{4}$ by neutral bis-thiourea hosts. Tetrahedron 53, 1647-1654.

(25) Still, W. C., Kahn, M., Mitra, A. (1978) J. Org. Chem. 43, 2923-2926.

(26) Balacco, G. (1994) SwaN-MR: A Complete and Expansible NMR Software for the Macintosh. J. Chem. Inf. Comput. Sci. 34, 1235-124.

(27) Scudiero, D. A., Shoemaker, R, H., Paull, K. D., Monks, A., Tierney, S., Nofziger, T. H., Currens, M. J., Seniff, D. Boyd, M. R. (1988) Evaluation of a soluble tetrazolium/formazan assay for 
cell growth and drug sensitivity in culture using human and other tumor cell lines. Cancer Res. 48, 4827-4833.

(28) Guidance Document on the Recognition Assessment and Use of Clinical Signs as Human Endpoints for Experimental Animals Used in Safety Evaluation. OECD Environmental Health and Safety Monograph. Series on Testing and Assessment No. 19 (2000).

(29) Nicolazzi C, Mignet N, de la Figuera N, Cadet M, Ibad RT, Seguin J, Scherman D, Bessodes M. (2003) Anionic polyethyleneglycol lipids added to cationic lipoplexes increase their plasmatic circulation time J. Controlled Release 88, 429-443.

(30) Mac Kay, A. F., Tarlton, E. J., Petri, S. I., Steyermark, P. R., Mosley, M. A. (1958) Amino Acids. V. 1,3-di-( $\omega$-carboxyalkyl)-thioureas and their chemistry, Can. J. Chem. 80, 1510-1517.

(31) Byk, G., Dubertret, C., Escriou, V., Jaslin, G., Rangara, R., Pitard, B., Crouzet, J., Wils, P., Schwartz, B., Scherman, D. (1998) Synthesis, activity, and structure-activity relationship studies of novel cationic lipids for DNA transfer. J. Med. Chem. 41, 224-235.

(32) Boussif, O., Lezoualc'h, F., Zanta, M. A., Mergny, M. D., Scherman, D., Demeneix, B., Behr, J. P. (1995) A versatile vector for gene and oligonucleotide transfer into cells in culture and in vivo: polyethylenimine. Proc. Natl. Acad.Sci. U.S.A. 92, 7297-301.

(33) Campbell, M. J. (1995) Lipofection reagents prepared by a simple ethanol injection technique. Biotechniques 18, 1027-1032.

(34) Bangham, A. D., Standish, M. M., Waltkins, J. C. (1965) Diffusion of univalent ions across the lamellae of swollen phospholipids. J. Mol. Biol. 13, 238-252.

(35) Delattre, J., Couvreur, P., Puisieux, F., Philippot, J.R., Schuber, F. (1993) Les liposomes, Aspects technologiques, biologiques et pharmacologiques. Ed. Inserm 54-62. 
(36) Tranchant I., Thompson B., Nicolazzi C., Mignet N., Scherman D. (2004) Physicochemical optimisation of plasmid delivery by cationic lipids. J Gene Med. S24-35.

(37) Nicolazzi, C., Mignet, N., de la Figuera, N., Cadet, M., Ibad, R. T., Seguin, J., Scherman, D., Bessodes, M. (2003) Anionic polyethyleneglycol lipids added to cationic lipoplexes increase their plasmatic circulation time. J. Controlled Release 88, 429-443.

(38) Simberg, D., Weisman, S., Talmon, Y., Faerman, A., Shoshani, T., Barenholz, Y. (2003) The role of organ vascularization and lipoplex-serum initial contact in intravenous murine lipofection. J. Biol. Chem. 278, 39858-65.

(39) Takakura, Y., Mahato, R. I., Hashida, M. (1998) Extravasation of macromolecules. Adv. Drug Deliv. Rev. 34, 93-108.

(40) Gilot, D., Miramon, M. L., Benvegnu, T., Ferrieres, V., Loreal, O., Guguen-Guillouzo, C., Plusquellec, D., Loyer, P. (2002) Cationic lipids derived from glycine betaine promote efficient and nontoxic gene transfection in cultured hepatocytes. J. Gene Med. 4, 415-27.

(41) Ferrari, E., Rusalov, D., Enas, J., Wheeler, C. (2002) Synergy between cationic lipid and co-lipid determines the macroscopic structure and transfection activity of lipoplexes. Nucl. Acids Res. 30, 18081816.

(42) Sijbren O., Janout, V., DiGiorgio, A., Young, M. C., Regen, S. L. (2000) Detection of Nonideal Mixing of Phospholipids in Fluid Bilayers J. Am. Chem. Soc., 122, 1200 -1204.

(43) Gabizon, A., Shmeeda H, Zalipsky S. (2006) Pros and cons of the liposome platform in cancer drug targeting. J. Controlled Release. 16, 175-183.

(44) Blanco, J. L., Bootello, P., Benito, J. M., Mellet, O., Fernandez, G. Urea-, thiourea-, and guanidine- as phosphate binders in water. (2006) J Org Chem. 71, 5136-43. 
Scheme title

Scheme 1: Preparation of lipopolythiourea (i) NHS, DCC, THF, RT. (ii) TFA, $\mathrm{CH}_{2} \mathrm{Cl}_{2}$, RT. (iii) DIPEA, 5, $\mathrm{CH}_{2} \mathrm{Cl}_{2}, \mathrm{RT}$. 
Scheme 1
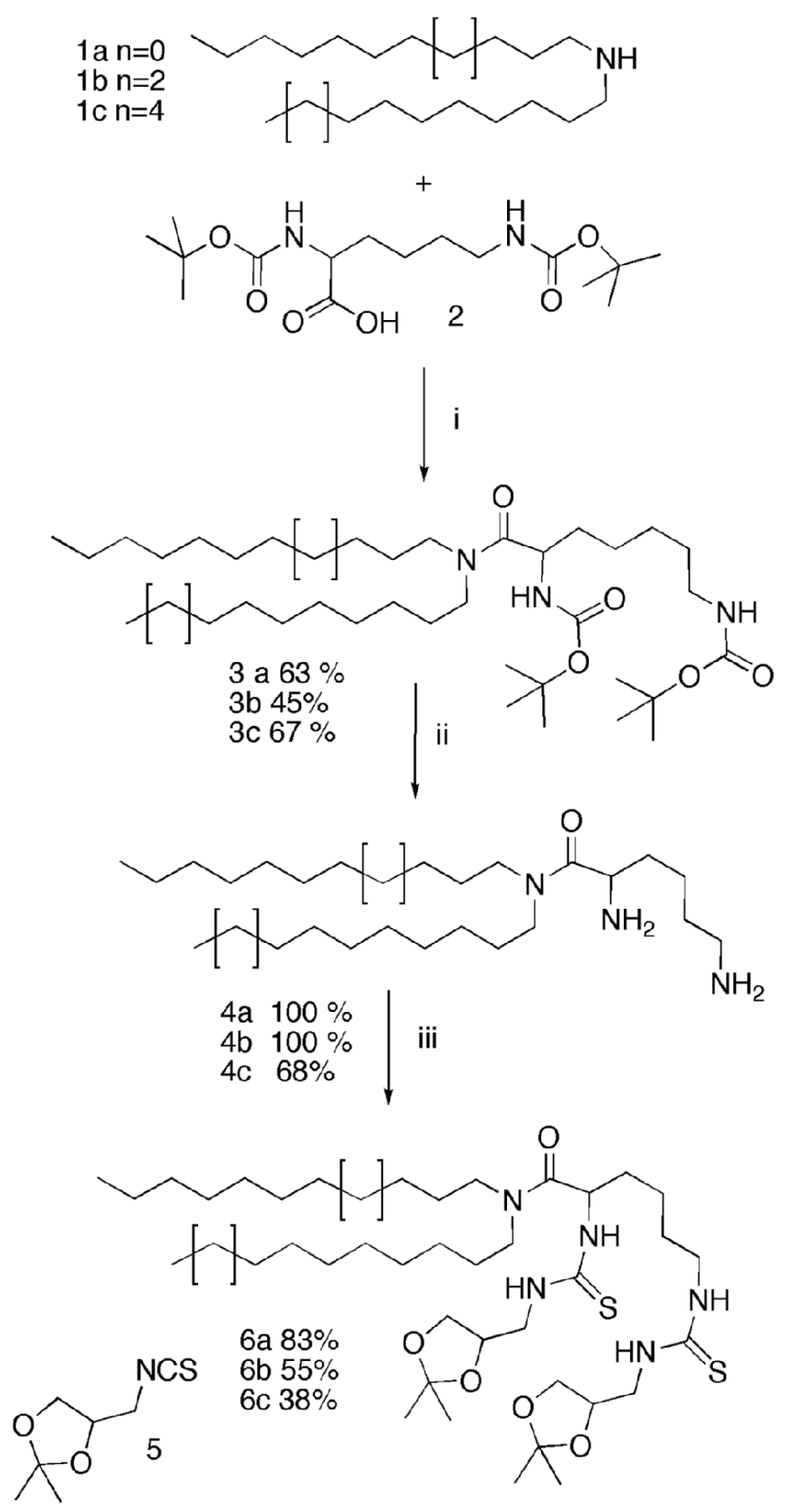
Figure Captions

\section{Figure 1.}

Complexes LPT/DNA (20 LPT/P, prepared by ethanolic injection) as well as the cationic lipid RPR209120 were incubated for 6 and $24 \mathrm{~h}$ in $10 \%$ serum at $37^{\circ} \mathrm{C}$, then treated with SDS $2 \%$ and EDTA $0.5 \mathrm{M}$ and loaded on an $1 \%$ agarose gel containing in TBE $(1 \mathrm{x}) 0.05 \%$ of SDS $(80 \mathrm{~V} / \mathrm{cm})$. Complexes were revealed by ethidium bromide staining.

\section{Figure 2.}

2-\{3-[Bis-(3-amino-propyl)-amino]-propylamino\}-N-ditetradecylcarbamoyl methyl-acetamide (RPR209120) and Polyethyleneimine (PEI) used as reference transfecting agents.

\section{Figure 3.}

Hydrodynamic diameter (lozenge symbols, right scale) and gene transfection (bars, left scale), measured by luciferase activity of LPT/DNA complexes at 20 and 40 TU/P ratios after $48 \mathrm{~h}$ incubation on B16 cells in presence of serum. LPT/DNA complexes were prepared by ethanolic injection at 20 and 40 TU/P in $\mathrm{H}_{2} \mathrm{O}$. RPR209120/DOPE/DNA lipoplexes was prepared $\mathrm{N} / \mathrm{P}$ ratio $=8$ in $\mathrm{NaCl} 150 \mathrm{mM}$. PEI/DNA polyplexes were prepared at $\mathrm{N} / \mathrm{P}=15$ in glucose $5 \%$. The complexes were then added to the cells in DMEM $+10 \% \mathrm{FBS}$ at $37^{\circ} \mathrm{C}$. Results are expressed as the mean of an experiment performed in triplicate errors bars indicating standard error of the mean.

\section{Figure 4.}

$\mathrm{IC}_{50}$ of $\mathbf{6 c} / \mathrm{DPPC}$ formulated by $($ left $)$ ethanolic injection $\left(\mathrm{IC}_{\mathrm{s} 0}=14.96 \mu \mathrm{M}\right)$ and $($ right $)$ hydration method, determined by a MTT test in vitro.

\section{Figure 5.}

Biodistribution of rhodamine-labeled particles $2 \mathrm{~h}$ after intravenous injection in mice bearing 3LL subcutaneous tumors. RPR209120/DOPE were prepared in $\mathrm{NaCl} 150 \mathrm{mM}$ and 6c/DPPC were prepared 
by hydration film method. Results are expressed as the percentage of the injected dose. $(* * \mathrm{p}<0.01$ by the Mann-Whitney U - test, significant in blood and lung, not in the tumor and RES)

\section{Figure 6.}

Comparison of gene transfection levels of lysine derivatives LPT (white bars) and previously published LPT (20) (grey bars) according to their ratio TU/P and chain length. Lysine LPT structures 10C, 12C, 14C correspond to $\mathbf{6 a}, \mathbf{6 b}, \mathbf{6 c}$ respectively. Previously published LPT structures 10C, 12C, 14C correspond to compounds $\mathrm{Ic}, \mathrm{Ib}$ and Ia represented on figure 7. Luciferase activity of LPT/DNA complexes at 20 and $40 \mathrm{TU} / \mathrm{P}$ ratios was measured after $48 \mathrm{~h}$ incubation on B16 cells in presence of serum. RPR209120/DOPE/DNA lipoplexes were prepared N/P ratio = 6 in $\mathrm{NaCl} 150 \mathrm{mM}$. Results are expressed as the mean of an experiment performed in triplicate errors bars indicating standard error of the mean.

\section{Figure 7.}

Previously published lipopolythiourea and thiourea compounds: I-II (20), III-V (19), VI (44). 
Figure 1

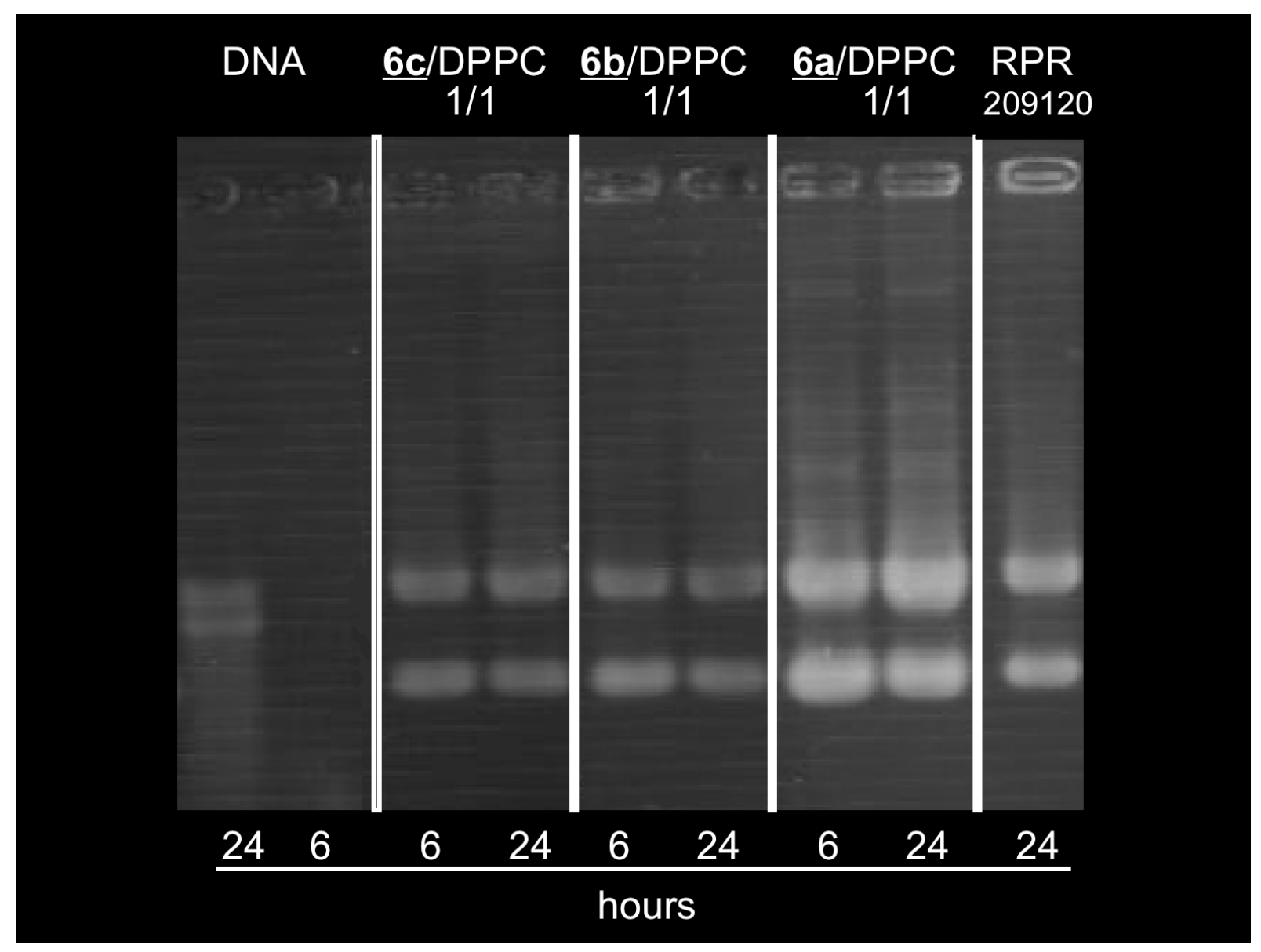


Figure 2

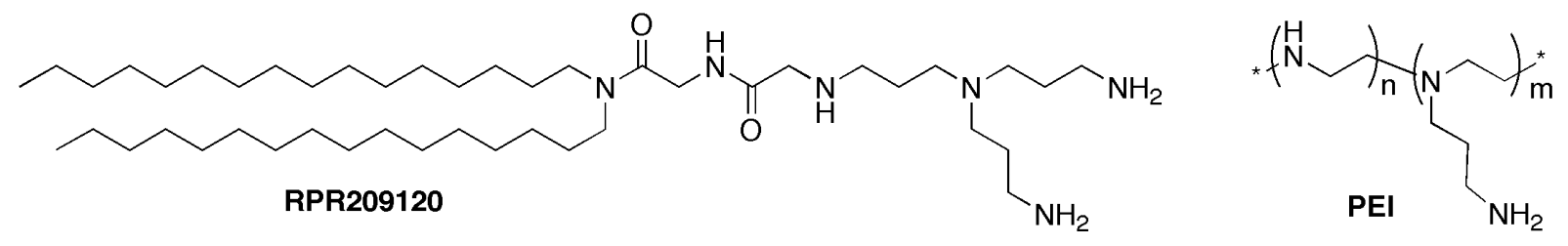


Figure 3

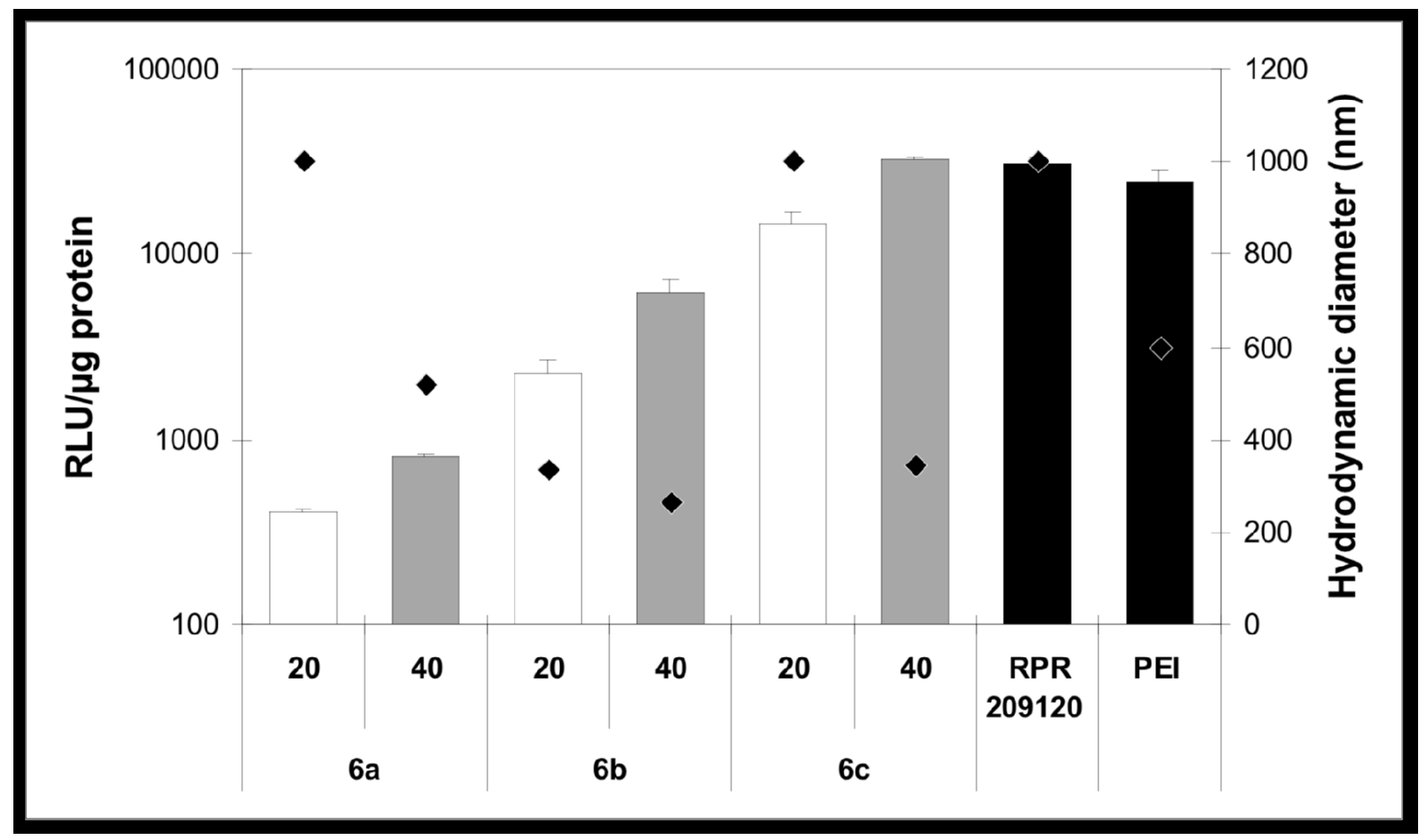


Figure 4
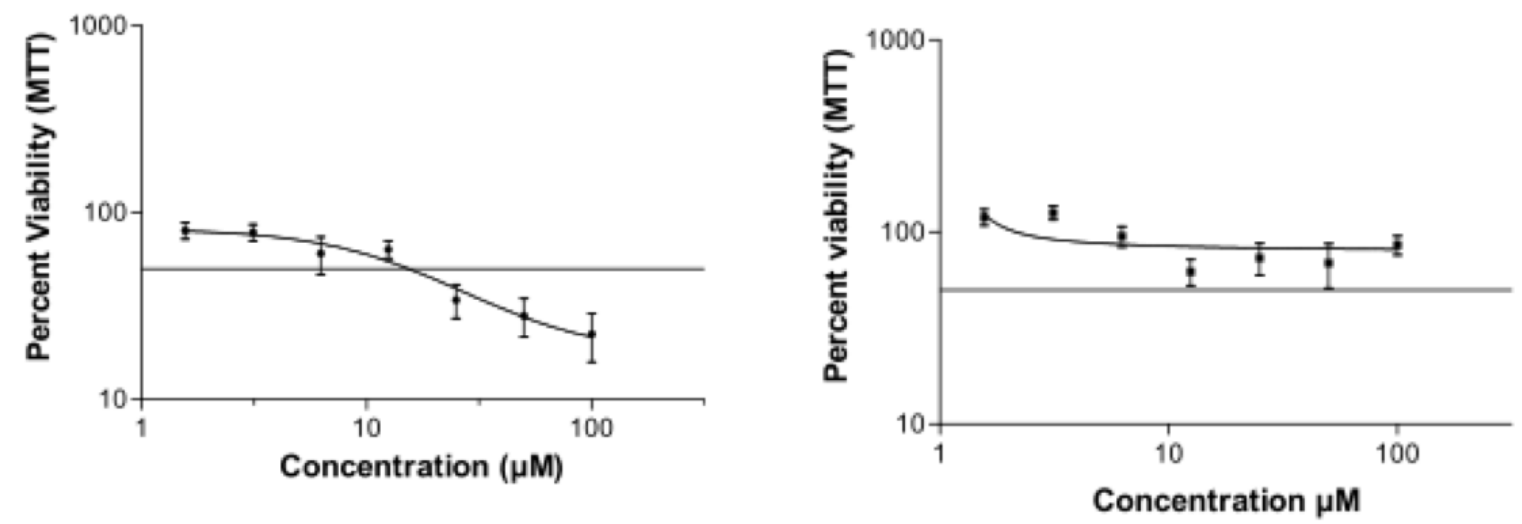
Figure 5
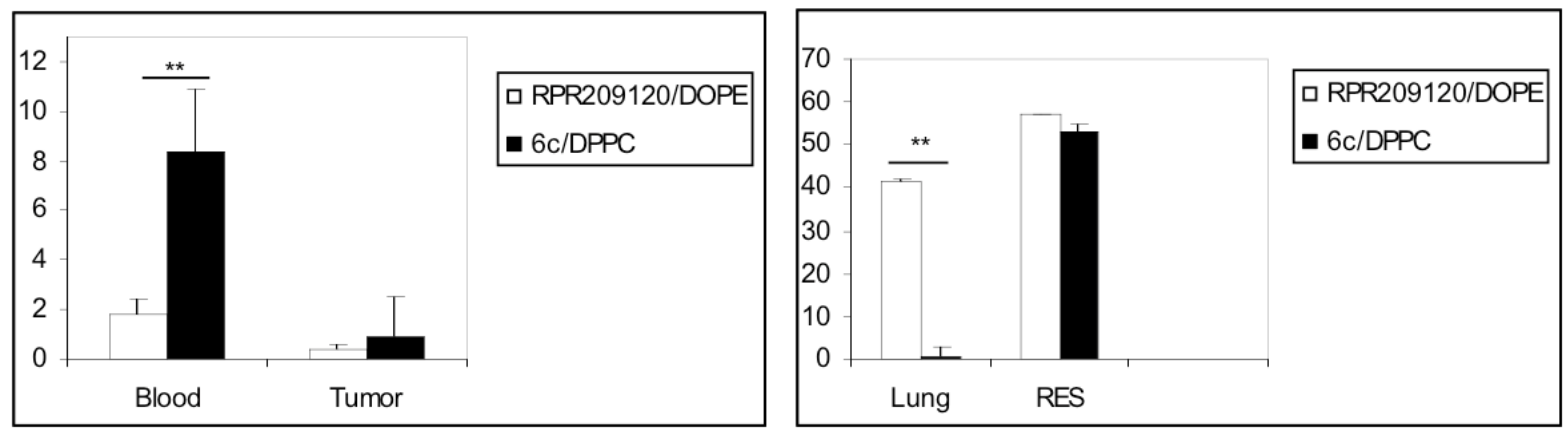
Figure 6

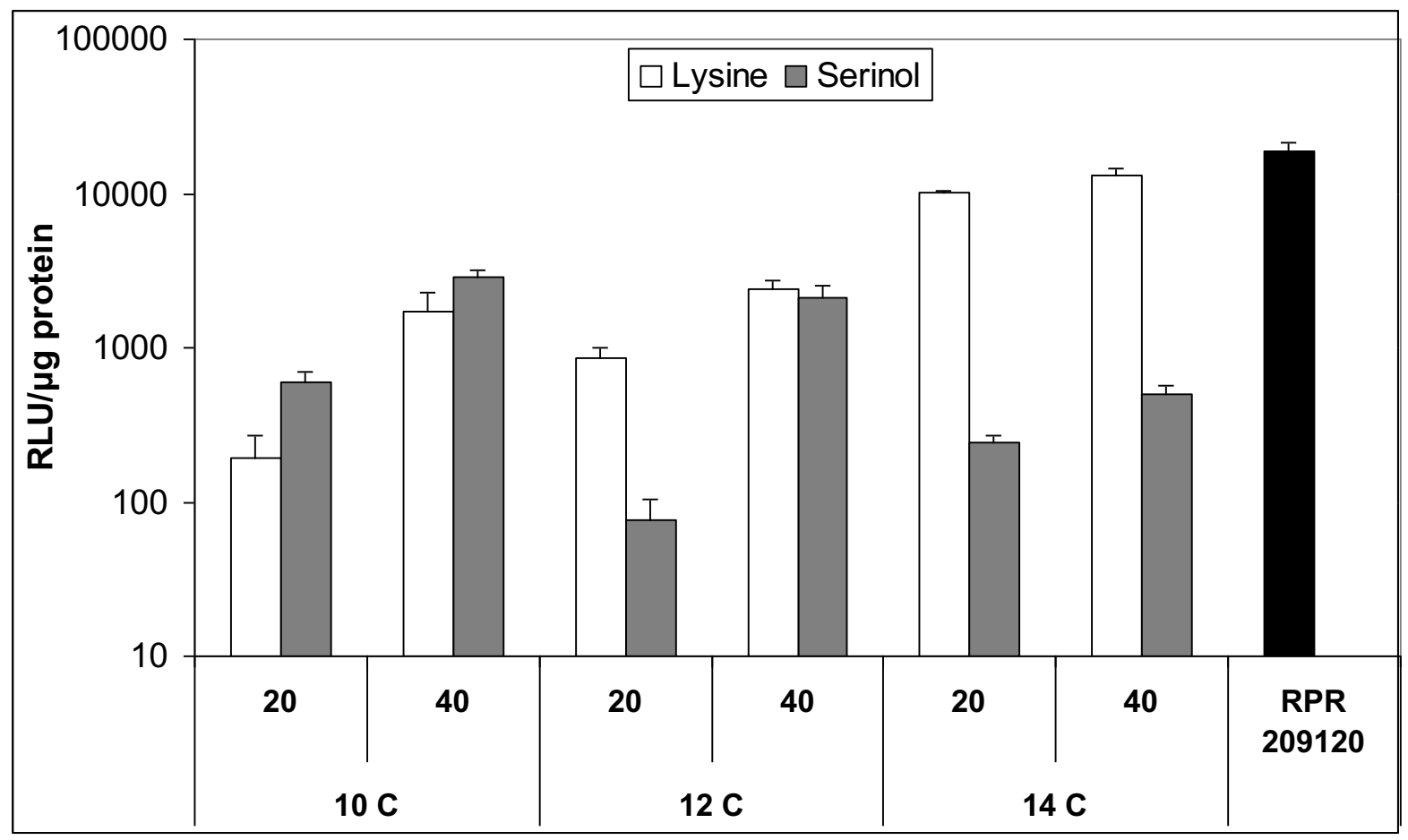


Figure 7 


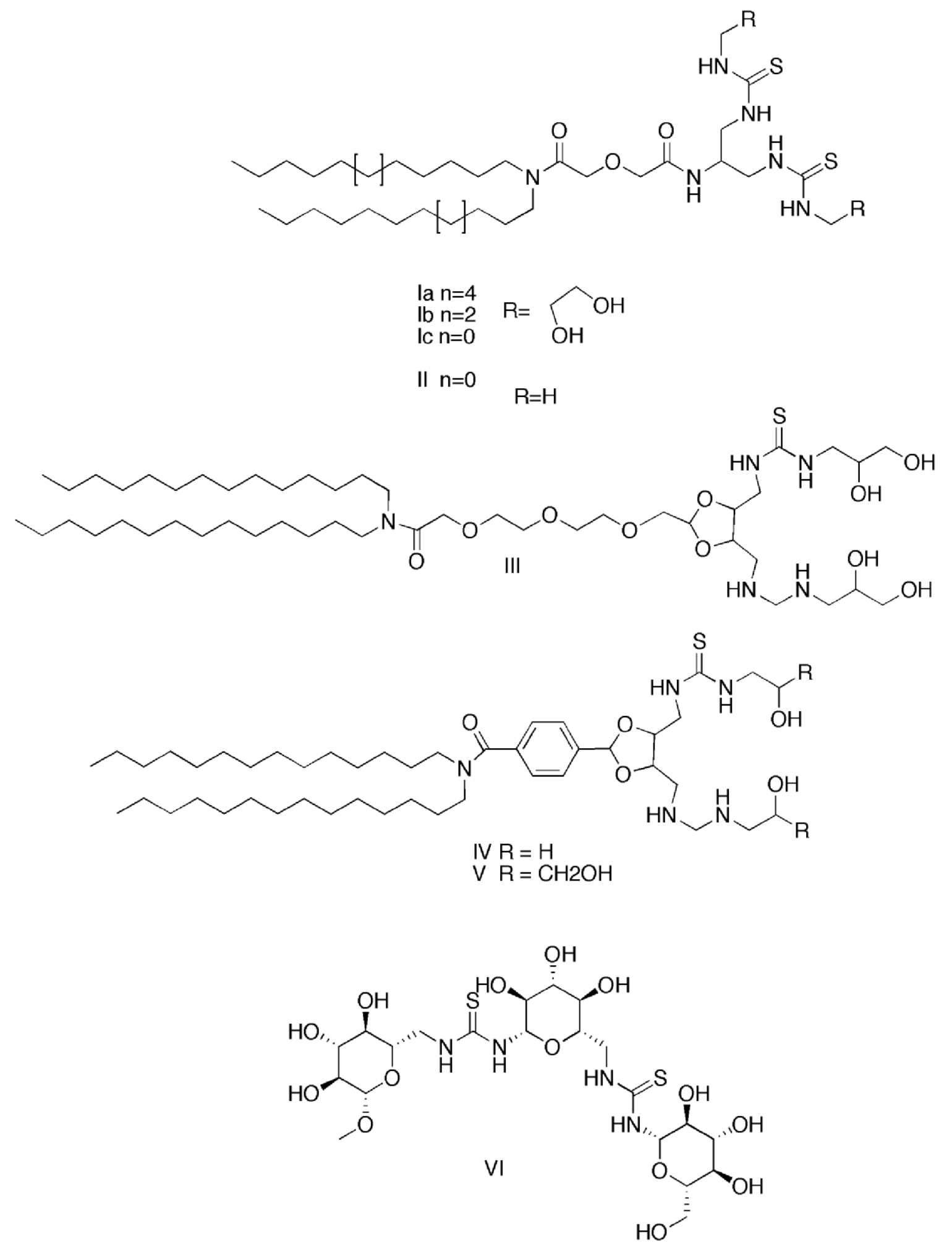

